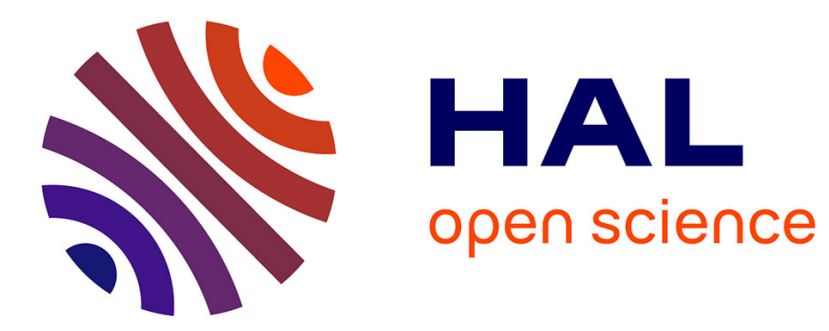

\title{
Experimental and numerical investigation of the infiltration heat load during the opening of a refrigerated truck body
}

T Lafaye de Micheaux, M Ducoulombier, Jean Moureh, V Sartre, J Bonjour

\section{- To cite this version:}

T Lafaye de Micheaux, M Ducoulombier, Jean Moureh, V Sartre, J Bonjour. Experimental and numerical investigation of the infiltration heat load during the opening of a refrigerated truck body. International Journal of Refrigeration, 2015, 10.1016/j.ijrefrig.2015.02.009 hal-01286912

\section{HAL Id: hal-01286912 \\ https://hal.science/hal-01286912}

Submitted on 11 Mar 2016

HAL is a multi-disciplinary open access archive for the deposit and dissemination of scientific research documents, whether they are published or not. The documents may come from teaching and research institutions in France or abroad, or from public or private research centers.
L'archive ouverte pluridisciplinaire HAL, est destinée au dépôt et à la diffusion de documents scientifiques de niveau recherche, publiés ou non, émanant des établissements d'enseignement et de recherche français ou étrangers, des laboratoires publics ou privés. 


\title{
EXPERIMENTAL AND NUMERICAL INVESTIGATION OF THE INFILTRATION HEAT LOAD DURING THE OPENING OF A REFRIGERATED TRUCK BODY
}

\author{
T. LAFAYE DE MICHEAUX ${ }^{(a)}$, M. DUCOULOMBIER ${ }^{(a)}$, J. MOUREH $^{(\mathbf{b})}$, V.SARTRE $^{(\mathrm{a})^{*}}$, \\ J. BONJOUR ${ }^{(\mathbf{a})}$ \\ (a) INSA-Lyon, CETHIL, CNRS, UMR5008, F-69621, Villeurbanne, France \\ (b) Irstea, UR GPAN, 1 rue Pierre-Gilles de Gennes, 92761 Antony, France \\ *valerie.sartre@insa-lyon.fr
}

\begin{abstract}
The present article deals with an experimental and numerical investigation of heat and mass infiltration rates during the opening of a refrigerated truck body. Experiments were carried out for different temperatures and different aperture ratios. The infiltration dynamics was found to involve two distinct phenomena: a buoyancy driven flow and a boundary layer flow. The first is a density-driven flow which gives birth to an important heat load peak. The second phenomenon is due to quasi steady-state natural convection over the inner wall of the truck. In the present work, the infiltration phenomenon was first analysed by means of a computational fluid dynamics model. The infiltration flow rate is well predicted except at the transition between both flow regimes. An analytical model using the ideal flow theory was also developed to model the buoyancy driven flow. The natural convection boundary layer flow is then well predicted using a classical method.
\end{abstract}

\section{NOMENCLATURE}

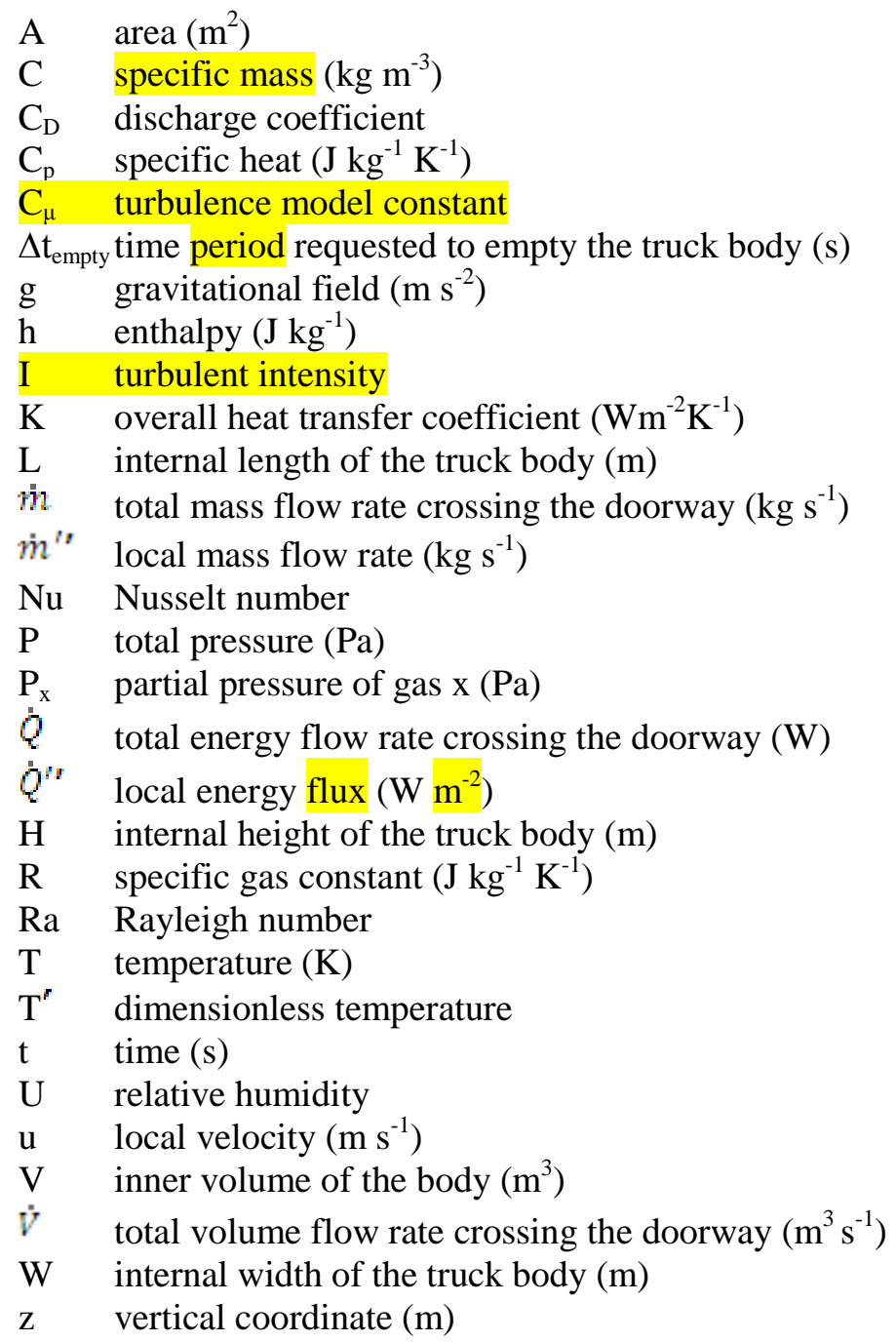




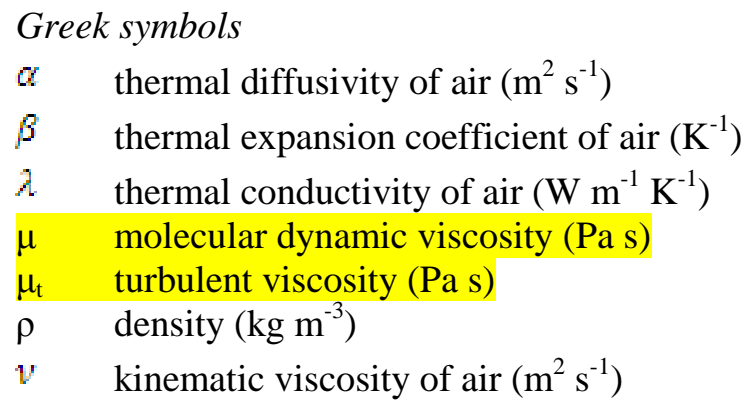

\section{Exponent}

0 initial

\begin{tabular}{ll}
\multicolumn{2}{l}{ Subscript } \\
air & internal air \\
ap & aperture \\
atm & atmosphere \\
da & dry air \\
dyn & dynamic \\
i & internal \\
0 & ambient \\
nc & natural convection \\
s & sensible \\
tot & total \\
W & wall \\
w & water vapour \\
ws & saturated water vapour
\end{tabular}

\section{INTRODUCTION}

Delivery of perishable food products is probably the most energy-consuming kind of road freight transport. Trucks are generally equipped with independent diesel engine-driven refrigeration units. In such distribution, the fuel consumption induced by the refrigeration system can be up to $30 \%$ of the vehicle engine consumption (Tassou et al., 2009). In urban environment, chilled and frozen foods are delivered during multi-drop rounds, which may require the use of multi-compartment (multi-temperature) vehicles. Based on a theoretical approach for urban distribution from wholesale depots to independent retailers, Repice and Stumpf (2007) evaluate that the energy demand of the refrigeration unit could be $15 \%$ higher than that of long distance primary distribution. In the context of energy consumption reduction for urban distribution, a better skill for the efficient design and operation of refrigerated trucks is needed. This implies an accurate evaluation of each heat load factor. The most obvious contribution to the load is the conduction heat gains through the walls of the insulated container. The assessment of which is required by the International Carriage of Perishable Foodstuff agreement (ATP agreement; United Nation, 2013). However, this simple one-factor approach is definitely not sufficient for multi-drop urban distribution. Indeed, the infiltration heat load due to the frequent door openings may represent a significant part of the total load applied to the truck body, exceeding the remaining contributions (e.g. solar radiation and heating from lights, fans and the defrost system). Besides, a frequent door opening could also alter the food quality. For this reason, the DIN8959 standard (DIN, 2000) takes the infiltration load into account and provides an assessment method. A quick application of this method for typical conditions shows that the infiltration heat load could come to the same order of magnitude as (or even nearly $30 \%$ higher than) the conduction heat gains.

Many investigations have been carried out to quantify air interchange rate through doorways of large refrigerated warehouses (up to $20000 \mathrm{~m}^{3}$ ) with short opening times (less than one minute). In those conditions, the build-up of the flow pattern is very fast and the infiltration reaches a steady state in less than 3 s (Hendrix et al., 1989; Azzouz et al., 1993). Hence, researchers have developed expressions for steady- 
state heat infiltrations based on the ideal flow theory (Brown and Solvason, 1963; Tamm, 1965; Fritzsche and Lilienblum, 1968; Gosney and Olama, 1975; Pham and Oliver, 1983). On the contrary, very few experimental results are available for smaller cavities (truck bodies, cold rooms or containers).

Foster et al. (2002) experimentally and numerically studied the air infiltration through the doorway of a $120 \mathrm{~m}^{3}$ cold room. The initial temperature of the cold room was set between $-25^{\circ} \mathrm{C}$ and $5^{\circ} \mathrm{C}$. Experiments were performed for two different openings $\left(0.3\right.$ and $\left.7.4 \mathrm{~m}^{2}\right)$. The infiltration velocity was measured by means of Laser Doppler Anemometry and vane anemometer. The door opening time ranged from 10 to $40 \mathrm{~s}$. Foster et al. observed that when using the small door, the temperature of the room did not change significantly. For the large door, they noticed that the air flow rate is decreasing during the door opening time. In a following study (Foster et al., 2003) the same authors developed a CFD model. The whole cold room and part of the experimental room were meshed. The initial temperature of the cold room was assumed to be homogeneous. The validity of this hypothesis was verified by Lafaye de Micheaux et al. in a numerical study (2013). The numerical model of Foster et al. (2003) was in good agreement with experimental results: the experimental velocity gradients and the neutral level (defined as the level in the doorway at which the pressure inside is equal to the pressure outside) were well predicted. The model brought to the fore the existence of three different air flow regimes. The first regime corresponds to the development of the flow; the second regime is defined at the steady state when the infiltration flow rate is constant. During the third regime, the infiltration flow rate is decreasing because of the decrease of the temperature difference (driving force) between the inside and outside air. By comparing different analytical models, CFD and experimental results Foster et al. concluded that their CFD model was not fine enough to accurately predict the steady state flow and that Gosney and Fritzsche $(1975 ; 1968)$ analytical models were more accurate. Besides, accuracy of the model was better for long door opening times.

Tso et al. (2002) experimentally studied air infiltration through the $0.9 \mathrm{~m}^{2}$ doorway of a $7.2 \mathrm{~m}^{3}$ refrigerated truck body. Temperature and humidity were measured before the opening of the door, during the infiltration and after closing the door. Sensible and latent heat loads from the external air were taken into account but not the heat conduction through the wall. The authors modeled the inside air volume as one node over the door opening time, with an average enthalpy and an average mass of moist air. By means of energy and mass balances they deduced the enthalpy load and mass infiltration over a door opening time of $2 \mathrm{~min}$. They obtained a total heat exchange rate across the door of $3.27 \mathrm{~kW}$.

Clavier et al. (2011) experimentally investigated the infiltration through the doorway of a medium-size refrigerated truck body. The aim of their study is to compare the heat load with and without two types of air curtain. Experiments were carried out in a climatic tunnel with accurately measured but non controlled outdoor relative humidity. These experiments show for the unprotected door and an opening time of $18 \mathrm{~min}$ an average infiltration heat load of $5.7 \mathrm{~kW}$.

As observed by Foster et al. $(2002,2003)$, for smaller cavities, the thermal inertia of the inner air volume is necessarily limited which leads to a decline of the air interchange rate with time. This peculiar transient infiltration mechanism still needs to be analysed in depth to properly predict the heat load variation as a function of time and to get an accurate estimation of the energy input over the opening time of the truck body. Thus, the present paper outlines the results of experimental and numerical investigations on the infiltration heat and mass flows across the doorway of a medium-size truck body (12-ton rigid truck). In order to propose a first-step phenomenological interpretation, a simple case was studied, i.e. the infiltration through an unprotected doorway (no plastic strip, no air curtain) of a single-compartment insulated body with no foodstuff stored in.

\section{EXPERIMENTAL SET-UP}

Experiments were led in a climatic tunnel dedicated to ATP tests. Such a facility offers the advantage that the temperature of the ambient air and its velocity can be easily controlled. Conversely, the humidity parameter was not controlled. Figure 1 illustrates the tunnel operating mode. If no vehicle engine is running, the air mainly follows a closed loop. The air is first sucked at the rear of the tunnel into a suspended ceiling where it successively passes through heating resistors and heat exchangers fed with chilled water. This cold water comes from a buffer tank kept at a constant temperature thanks to a refrigeration system. The dual control of the resistors heating power and the chilled water flow rate (three-way valve) permits to control the temperature of the air at the exit of the HVAC system. Finally, the air is blown back at the front of the tunnel. 
The tunnel was $31 \mathrm{~m}$ long, $5.5 \mathrm{~m}$ wide and $5.43 \mathrm{~m}$ high, i.e. had a $926 \mathrm{~m}^{3}$ inner volume. The tested insulated body was not fixed to the truck chassis but put on wheels directly on the floor of the tunnel. Its outer dimensions were $2.6 \times 2.6 \times 5.68 \mathrm{~m}$ (height $\times$ width $\times$ length) and its inner dimensions were $2.35 \times 2.5 \times 5.51 \mathrm{~m}$, i.e. $32.4 \mathrm{~m}^{3}$ inner volume. The body walls were composed of polyurethane foam sandwiched between external and internal layers of glass-reinforced plastic (GRP). The overall heat transfer coefficient K (often called "K-value" in the field of refrigerated transportation) of the insulated body equipped with the cabinet sub-assembly was measured during preliminary tests and was found to be $\mathrm{K}=0.576 \mathrm{Wm}^{-2} \mathrm{~K}^{-1}$. The floor of the truck body was $335 \mathrm{~mm}$ above the ground because of the presence of rollers. The rear of the body was placed at the mid-length of the tunnel. As illustrated in Figure 2, the body was equipped with a rear 3-flap barn door which enabled different opening areas, i.e. full, 2/3 lateral, 1/3 lateral and 1/3 central apertures. It was also fitted with an electrically driven refrigeration unit having a 6.3 to $9.9 \mathrm{~kW}$ effective refrigerating capacity $\left(30{ }^{\circ} \mathrm{C}\right.$ sink temperature and -20 to $0{ }^{\circ} \mathrm{C}$ source temperature). Experiments were carried out for different initial temperatures inside and outside of the body prior to the door opening and for different aperture ratios.

Velocities and temperatures of the airstream were measured in the doorway plane (Figure 2). As the largest variations of those parameters were expected along the vertical direction, the instrumentation was arranged along this axis. A mobile vertical bar was fitted with 8 equally spaced velocity transmitters ( $280 \mathrm{~mm}$ pitch) and 17 thermocouples (140 mm pitch), as shown in Figure 3. Hot film anemometers were used (E+E Elektronik EE75) having a $1.5 \mathrm{~s}$ response time. Thermocouples were of type $\mathrm{K}$ and made of two welded 0.2 $\mathrm{mm}$ conductors, which ensured a low thermal inertia. Depending on the chosen configuration of the door opening, the bar supporting the instrumentation was shifted laterally a number of times to cover the total width of the doorway. For each new position of the bar a new test was carried out for the same temperature conditions. For a full opening, the doorway width was divided into five positions, named P1 to P5 in Figure 3. As depicted in Figure 4, three positions were chosen for the $2 / 3$ lateral opening ( 0.71 aperture ratio), and only one position was selected for both the $1 / 3$ central opening and the $1 / 3$ lateral opening (respectively, 0.36 and 0.29 aperture ratios).

The temperature was also measured at different locations in the body with the same miniature thermocouples. The inner wall temperature was recorded at the centre of each panel (floor, roof, front wall, side walls), as well as the air temperature at three equally spaced positions along the central vertical axis of the container (Figure 2). Lastly, a humidity transmitter and a temperature sensor were placed into the tunnel, $10 \mathrm{~m}$ backwards from the body rear face. No measurement of the relative or absolute humidity was made inside the insulated body. The uncertainties relative to the measurements are reported in Table 1.

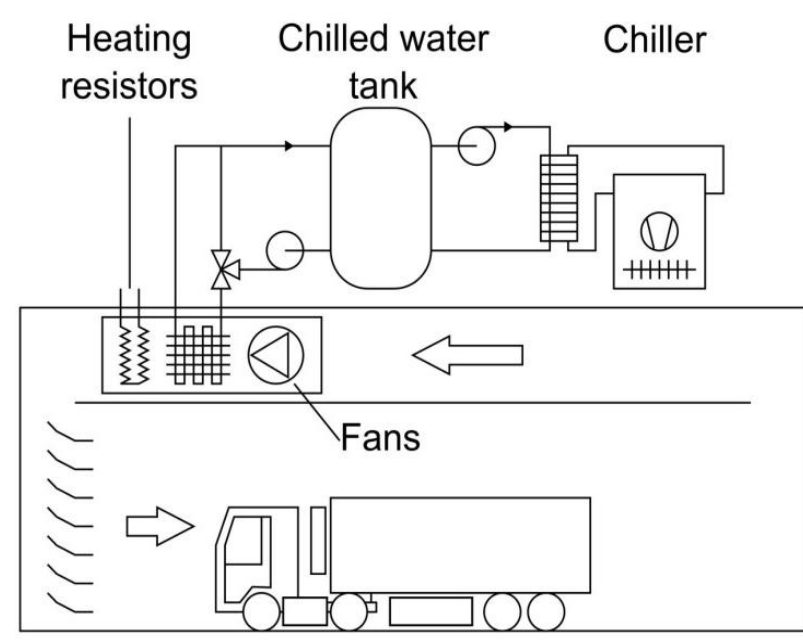

Figure 1: Operating diagram of the tunnel.

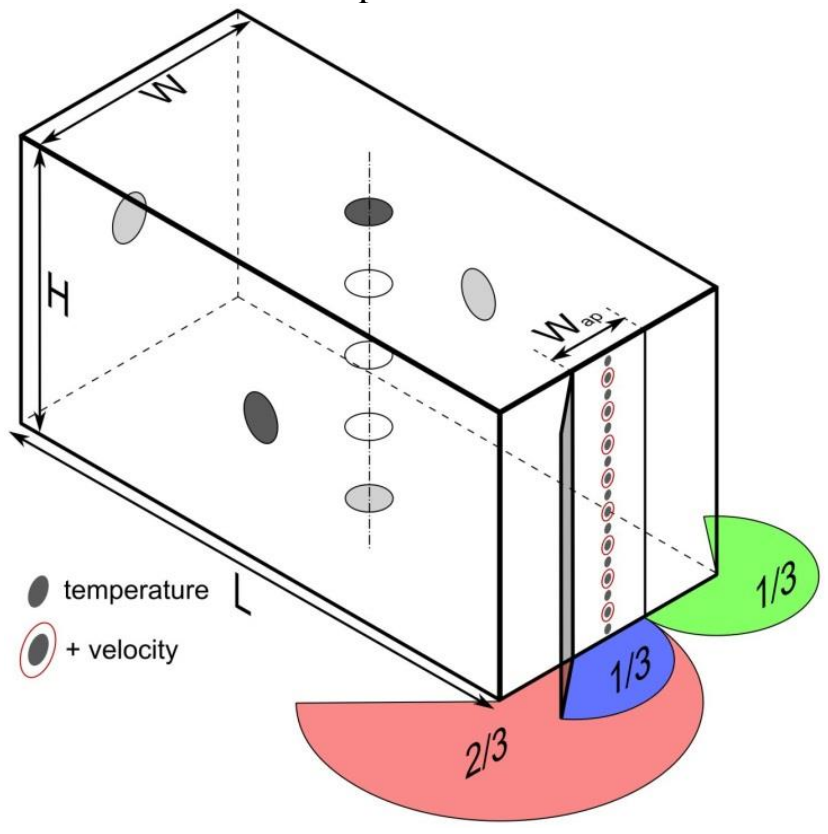

Figure 2: Truck body and associated instrumentation. 


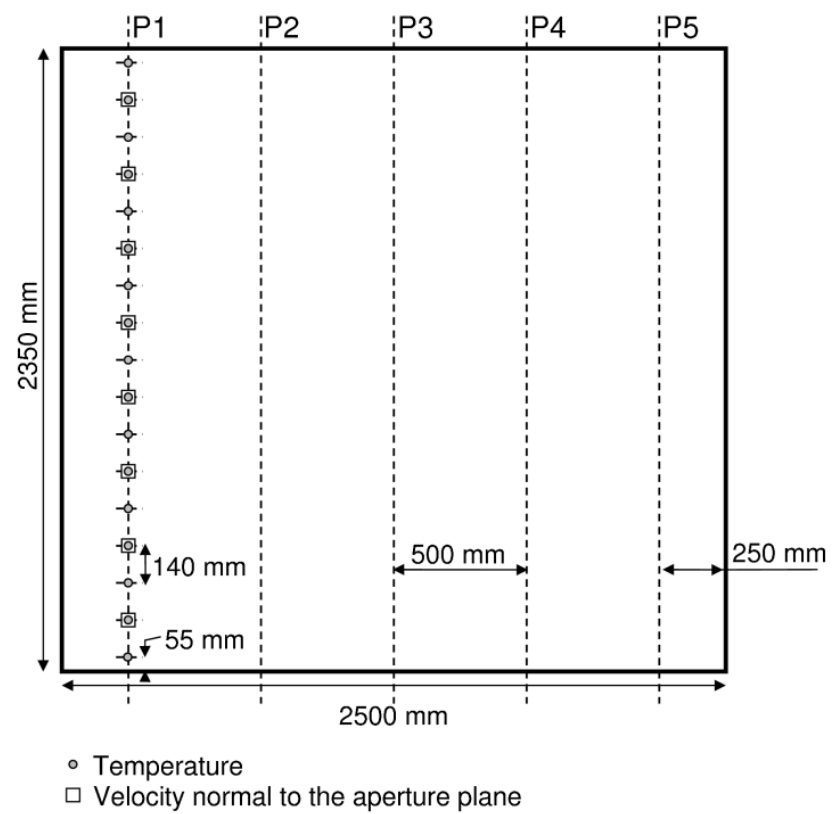

Figure 3: Location of the instrumentation in the doorway plane.

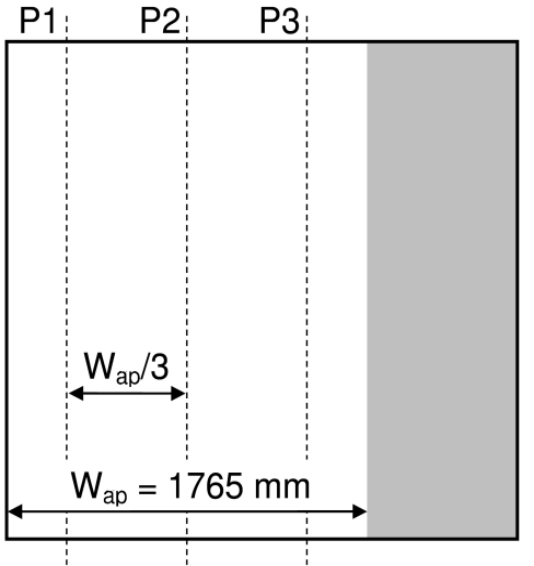

(a)

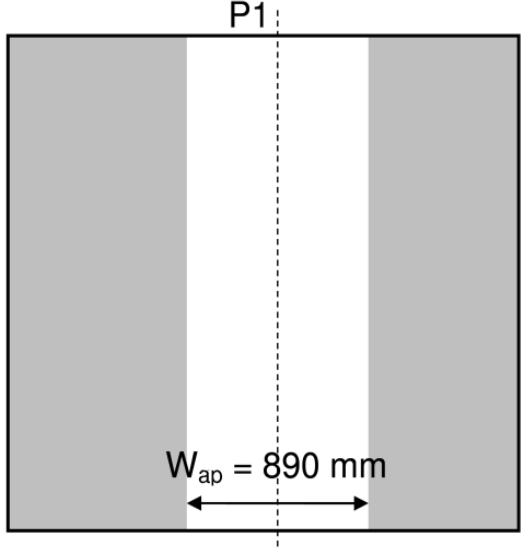

(b)

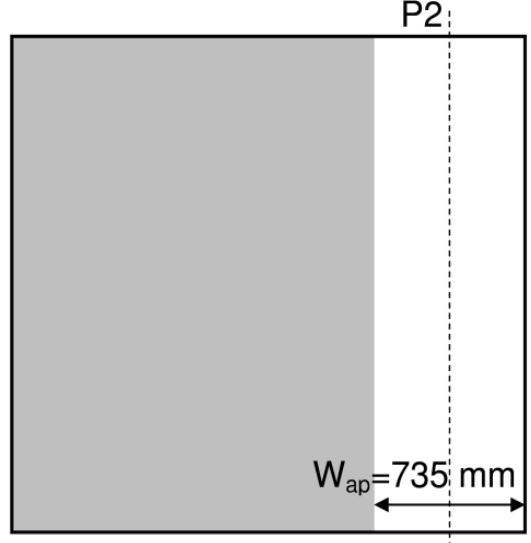

(c)

Figure 4: Specification of the different opening configurations:

(a) 2/3 lateral, (b) 1/3 central, (c) 1/3 lateral.

Table 1: Measurement uncertainties.

\begin{tabular}{|c|c|}
\hline Temperature & $\pm 0.5 \mathrm{~K}$ \\
\hline Velocity & \pm 0.1 to $0.14 \mathrm{~m} / \mathrm{s}$ \\
\hline Humidity & $\pm 1.5 \% \mathrm{rh}$ \\
\hline
\end{tabular}

Tests were carried out according to the following procedure, comprising the opening phase (infiltration) and the temperature recovery phase. The opening phase was launched once the inside and outside temperatures were settled around the set points. Then, the air conditioning system of the tunnel as well as the refrigeration unit of the container were stopped. A waiting period of $10 \mathrm{~s}$ was observed so that the inside and outside air velocity slowed down. Prior to the door opening, the data logger was activated with an acquisition period of $1 \mathrm{~s}$. From the opening time, velocities, temperatures and humidity were recorded during 10 to $15 \mathrm{~min}$. After this period, the measured quantities showed a constant drift with time, i.e. a quasi steady-state was reached. So, the acquisition system was stopped and the bar supporting the instrumentation was moved to a different position within the doorway. Then, the doors were closed, and the data logger was started again with a slower recording period of $15 \mathrm{~s}$. Meanwhile, the tunnel HVAC system and the truck refrigeration unit were also switched on to restore the temperature levels inside and outside of the container. The tunnel temperature reached the set point far before that of the refrigerated body. So, the temperature recovery criterion was 
based on the inner wall temperature of the body which took the most time to settle down. Typically a $1 \mathrm{~h} 20$ waiting period was needed to recover from the infiltration phase, and up to $2 \mathrm{~h} 20$ in the worst conditions.

For each set of inside temperature, outside temperature, and position of the instrumentation within the doorway, the measurements were carried out at least two times so as to check the repeatability of the experiments and the data sets were averaged to get a single record. For the full opening case, it was verified that the measurements made at location P4 and P5 ( $c f$. Figure 3) could be considered as respective duplicates of those made at location P2 and P1 due to the symmetry of the configuration. As a baseline experiment, a first measurement session was carried out for a $253 \mathrm{~K}$ inside temperature $\left(T_{i}^{0}\right)$, a $293 \mathrm{~K}$ outside temperature $\left(T_{o}\right)$, and a complete door opening. From this benchmark, the individual effects of the inside temperature, the outside temperature, and the aperture ratio were tested accordingly to Table 2.

\section{MODELLING APPROACH}

Besides the experimental investigation of the air infiltration, a Computational Fluid Dynamics (CFD) study was also carried out for the full aperture. 3D simulations were performed at transient regime, using a finite volume commercial software (STAR CCM+ v8.04).

\subsection{Domain}

Owing to the symmetry of the system, only half of the climatic tunnel without the HVAC system and half of the truck body were modelled. The domain was meshed using polyhedral cells. A gradual mesh refinement was applied in order to get pseudo-uniform meshes in the inner part of the truck body and coarser meshes at both ends of the tunnel. Close to the inner wall of the truck body, structured hexahedral cells meshes were used to predict the velocity with the relevant law of the wall. The so-called "high $y+$ wall treatment model" based on the conventional equilibrium logarithmic law was used (Launder and Spalding, 1974). The size ratio between two consecutive cells was kept below 1.2. The independency of the solution regarding the mesh size was studied for grids ranging from 18000 to 24000 cells: the solution was found to be gridindependent for 21000 cells.

\subsection{Boundary conditions, initial conditions and assumptions}

The modeled truck body was composed of one single material, having the thermal properties given in Table 3. The wall thickness was divided in at least 4 parts, each being assigned a node. A non-slip condition was applied at the wall.

A uniform pressure condition was fixed at the rear of the tunnel (Table 4). This condition was set to absorb a cold flow wave leaving the truck body, which otherwise would be reflected on the rear wall and would propagate back into the truck body. It could be verified that this condition would not influence the infiltration flow over $30 \mathrm{~s}$ after the door opening. At the other wall of the tunnel, a non-slip condition for the velocity and an adiabatic condition for the heat flow were applied.

The air was modeled as dry and supposed to follow the ideal gas law. The gravity was taken into account. The temperature of the walls of the truck body and the inner air were initialized at $253 \mathrm{~K}$ (base line case) or $273 \mathrm{~K}$, the air temperature inside the tunnel at $293 \mathrm{~K}$ (Figure 5). At the first time step, the cold inside air was directly in contact with the outside warm air, so as to simulate an instantaneous opening of the door. Simulations were only run for the full aperture.

Table 2: Experimental conditions tested in the present investigation.

\begin{tabular}{|c|c|c|c|c|}
\hline & \multicolumn{3}{|c|}{$T_{o}[\mathrm{~K}]$} \\
\hline & & $\mathbf{2 7 8}$ (80\%rh) & 293 (40\%rh) & $\mathbf{3 1 3}$ (15\% rh) \\
\hline \multirow{2}{*}{$T_{i}^{0}[\mathrm{~K}]$} & 273 & & $\square^{1} \Delta^{1 / 3}$ & $\square^{1} \Delta^{1 / 3}$ \\
\hline & 253 & $\square^{1} \Delta^{1 / 3}$ & $\square^{1}\left\langle\frac{2 / 3}{1 / 3}\right\rangle$ & $\square^{1} \Delta^{1 / 3}$ \\
\hline
\end{tabular}

Table 3: Thermal properties of the truck body.

\begin{tabular}{|c|c|c|c|c|}
\cline { 3 - 5 } \multicolumn{1}{c|}{} & $\begin{array}{c}\text { Conductivity } \\
\text { W/mK }\end{array}$ & $\begin{array}{c}\text { Thermal capacity } \\
\mathrm{J} / \mathrm{kgK}\end{array}$ & $\begin{array}{c}\text { Density } \\
\mathrm{kg} / \mathrm{m}^{3}\end{array}$ & $\begin{array}{c}\text { Thickness } \\
\mathrm{cm}\end{array}$ \\
\hline Ceiling & & & & 12.5 \\
\cline { 1 - 2 } Floor & \multirow{3}{*}{0.0679} & 1800 & 32 & 12.5 \\
\cline { 1 - 3 } Front wall & & & & 8.5 \\
\hline Lateral wall & & & 32 & 5 \\
\hline
\end{tabular}


Table 4: Boundaries conditions at the rear wall of the tunnel.

\begin{tabular}{|c|c|}
\hline Relative pressure $(\mathrm{Pa})$ & 0 \\
\hline Temperature $(\mathrm{K})$ & 293 \\
\hline Turbulent intensity & 0.01 \\
\hline Turbulent viscosity ratio & 10 \\
\hline
\end{tabular}

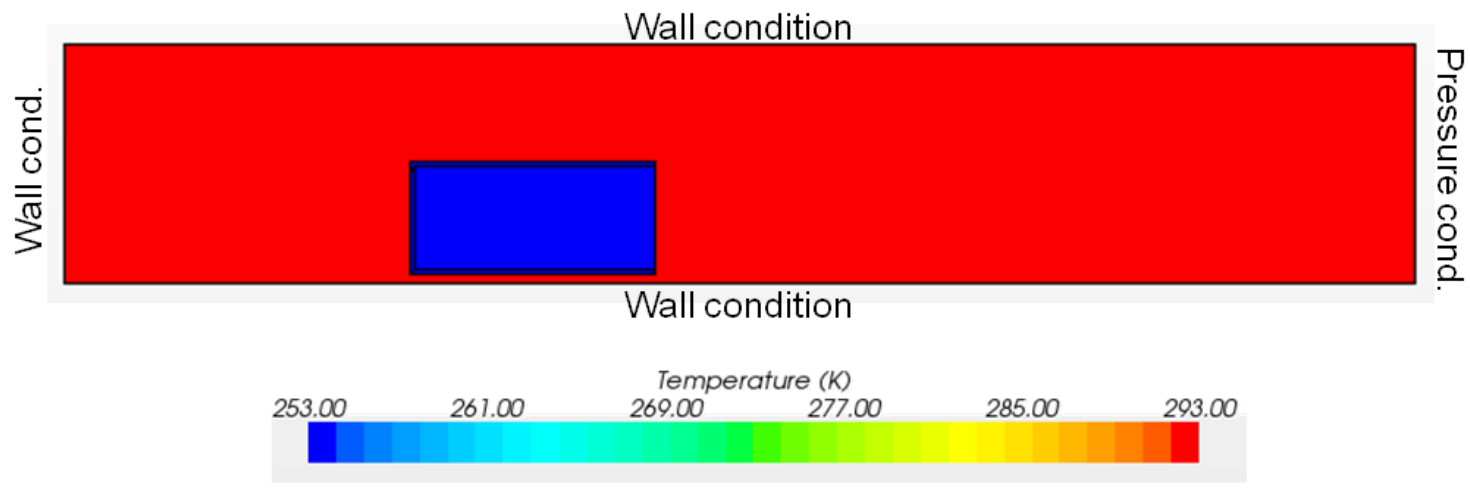

Figure 5: Boundary and initial conditions.

\subsection{Numerical resolution}

The time-averaged Navier-Stokes differential equations, for high-Reynolds numbers and incompressible flows were solved using a coupled solver for mass, momentum and energy equations. The realizable k- $\varepsilon$ turbulence model (Shih et al., 1995) was used with the second-order upwind numerical scheme. Turbulence at the pressure inlet is defined with the turbulent kinetic energy $\left(\mathrm{k}_{0}\right)$ and with the energy dissipation rate $\left(\varepsilon_{0}\right)$ :

$k_{0}=\frac{3}{2}(u I)^{2}$

$\epsilon_{0}=C_{\mu} \frac{\rho k_{0}^{2}}{\mu}\left(\frac{\mu_{t}}{\mu}\right)^{-1}$

Where:

$I=1 \%$ represents the turbulent intensity,

$C_{p}=0.09$ is a turbulence model constant

$\mu$ is the molecular dynamic viscosity (Pa s)

$\mu_{t}$ is the turbulent viscosity ( $\mathrm{Pa} \mathrm{s}$ )

$\frac{\mu_{t}}{u}=10$

The convergence was considered to be reached when all the normalized residuals were below $10^{-5}$. The independency of the solution regarding the time step was studied. Temperature and velocity profiles were compared every $10 \mathrm{~s}$ for different time step $(0.1,0.2$ and $0.5 \mathrm{~s})$. Its influence on the CPU time is given in Table 5. A time step of $0.2 \mathrm{~s}$ gives the same temperature profile as with a time step of $0.1 \mathrm{~s}$. By comparing velocity profiles with a time step of $0.1 \mathrm{~s}$ and $0.2 \mathrm{~s}$ it has been observed that the profiles were the same for $\mathrm{t}$ ranging from 0 to $15 \mathrm{~s}$ and from 35 to $60 \mathrm{~s}$. In order to reduce the calculation time, the time step has been changed depending on $\mathrm{t}$. The $0.2 \mathrm{~s}$ time step has been used for $\mathrm{t}=0 \mathrm{~s}$ to $\mathrm{t}=15 \mathrm{~s}$ and for $\mathrm{t}=35 \mathrm{~s}$ to $60 \mathrm{~s}$; the $0.1 \mathrm{~s}$ time step has been used between the date $\mathrm{t}=15 \mathrm{~s}$ and $\mathrm{t}=35 \mathrm{~s}$.

Table 5: Influence of time step on CPU time.

\begin{tabular}{|c|c|c|c|c|}
\cline { 2 - 5 } \multicolumn{1}{c|}{} & \multicolumn{3}{c|}{ Solution real time } & $\begin{array}{c}\text { Equivalent CPU time } \\
\text { (day) }\end{array}$ \\
\cline { 2 - 5 } \multicolumn{1}{c|}{} & $0-15 \mathrm{~s}$ & $15-35 \mathrm{~s}$ & $35-60 \mathrm{~s}$ & 12.5 \\
\hline \multirow{3}{*}{$\begin{array}{c}\text { Numerical } \\
\text { time step } \\
(\mathbf{s})\end{array}$} & \multicolumn{3}{|c|}{0.1} & 6 \\
\cline { 2 - 5 } & \multicolumn{3}{|c|}{0.2} & 2 \\
\cline { 2 - 5 } & 0.2 & 0.1 & 0.2 & 8 \\
\hline
\end{tabular}




\section{RESULTS AND DISCUSSION}

\subsection{Data reduction}

Three main quantities were determined from the measurements, which are the total flow rates of the volume $(\dot{V})$, the mass $(\dot{m})$ and the energy $(\dot{Q})$ crossing the doorway. The local fluxes of those quantities, respectively called $u, m^{* \prime \prime}$ and $Q^{\prime \prime}$, were first calculated at each location of a thermocouple on the aperture surface. As there were two times less velocity measurements than temperature sensors in the doorway plane ( $c f$. Figure 3 ), a linear interpolation was made between two successive anemometers in the vertical direction to get a velocity corresponding to each thermocouple. For each local brace of velocity and temperature, the mass flux of the moist air was calculated as follows:

$\dot{m}^{\prime \prime}=u\left(C_{w}+C_{d a}\right)$,

where $C_{w}$ and $C_{d a}$ are respectively the specific mass of the water vapour and dry air. They were determined from the perfect gas equation depending on the partial pressure of the water vapour $\left(P_{w}\right)$ and the thermodynamic temperature $(T)$ at each location:

$C_{w}=P_{w} /\left(R_{w} T\right)$

$C_{d a}=\left(P-P_{w}\right) /\left(R_{d a} T\right)$.

$R_{w}$ and $R_{d a}$ are the ideal gas mass constants for water and dry air, whereas $P$ is the total (atmospheric) pressure. For a given temperature, $P_{w}$ was set to the minimum value between (i) the water partial pressure of the outside air (derived from the temperature $\left(T_{o}\right)$ and the relative humidity $\left(U_{o}\right)$ measured in the climatic tunnel); and (ii) the water saturation pressure $\left(P_{w s}\right)$ corresponding to $100 \%$ relative humidity at the given temperature; that is:

$P_{w}(T)=\min \left\{U_{o} \times P_{w s}\left(T_{o}\right), P_{w s}(T)\right\}$.

Furthermore, the heat flux was derived from:

$\dot{Q}^{\prime \prime}=u\left(C_{w} h_{w}+C_{d a} h_{d a}\right)$,

where $h_{w}$ and $h_{d a}$ are the water and dry air enthalpies calculated from the following simplified expressions (Knochee et al., 1992):

$h_{w}[\mathrm{~kJ} / \mathrm{kg}]=2501+1.86 \times \theta\left[{ }^{\circ} \mathrm{C}\right]$,

$h_{d a}[\mathrm{~kJ} / \mathrm{kg}]=1.006 \times \theta\left[{ }^{\circ} \mathrm{C}\right]$.

Finally, the different fluxes (volume, mass and heat) were integrated over the whole aperture area. A first order Newton-Cotes method (trapezium equation) was used in the vertical direction for each position of the instrumentation in the doorway. Then, these results were integrated over the lateral direction using a zero order method (simple summation).

\subsection{Infiltration flow rate}

The time evolution of the volume flow rate for the full opening and for the baseline case (cf. section 2) is depicted in Figure 6. The experimental results show that the infiltration air flow does not establish instantaneously after the opening. Instead, the volume flow rate increases progressively due the development of the doorway flow pattern, i.e. hot air entering at the top of the opening and cold air flowing outside at the bottom. The maximum volume flow rate is nearly reached at $\mathrm{t}=10 \mathrm{~s}$ after the door opening. The model predicts a maximum volume flow rate slightly below the experimental one, $5 \mathrm{~s}$ after the door opening. This may be due to the instantaneous opening infiltration which is not occurring in the experiment. In addition, the infiltration involves a no-stationary transitional flow which is difficult to predict by means of RANS turbulence models. The maximum decreasing rate of the infiltration occurs after $15 \mathrm{~s}$ for the model and $20 \mathrm{~s}$ for the experiment. The green and red areas on Figure 6 represent the integral of the volume flow rate when equal to the body inner volume. The time required by the internal air to be renewed is therefore well predicted by the model and close to $16 \mathrm{~s}$. Beyond $30 \mathrm{~s}$, the infiltration stabilises in a quasi-steady state. The predicted infiltration flow rate is then twice lower than the experimental value, but included in the experimental uncertainty. Ducoulombier et al. (2011) observed that this state arises once the inside air temperature reaches a plateau of a few Kelvin $(\sim 3 \mathrm{~K})$ below the outside air temperature.

\subsection{Temperature field}


The predicted temperature field in the symmetry plane of the truck body is shown in Figure 7. As observed with the infiltration flow rate, at the date $t=20 \mathrm{~s}$ after the full door opening, the whole internal air of the body has been renewed. The quasi-steady state may thus be observed from $t=20 \mathrm{~s}$ to $\mathrm{t}=60 \mathrm{~s}$. During that period the external air flowing in at a temperature of $293 \mathrm{~K}$ is cooled down by the wall and leaves at a temperature of a few kelvins below the ambient. The temperature of the inner wall surfaces slightly increases by $2 \mathrm{~K}$ over this period of time of $60 \mathrm{~s}$.

Experimental and numerical temperature profiles in the symmetry plane of the doorway (P3) are compared in the Figure 8 . The ordinate of the graphs is the reduced height i.e. the ratio of the location along the vertical axis (counted from the bottom of the doorway) to the height of the aperture. These results involve two independent experiments $(\mathrm{N} 1, \mathrm{~N} 2)$ to check the repeatability. At $\mathrm{t}=5 \mathrm{~s}$ the repeatability of the measurements is not really satisfactory. This phenomenon may either be due to the opening protocol or to transient turbulence development. Nevertheless, $10 \mathrm{~s}$ after the opening the repeatability is improved. Temperature profiles are described over the first $60 \mathrm{~s}$ after the door opening.

- At t=10 s: the experimental and numerical results are in good agreement and exhibit in the upper part of the opening $(0.4-1)$ a flat profile, corresponding to the ambient temperature of the tunnel. In the lower part of the aperture $(0-0.4)$, where the inside air is flowing out, the temperature profile is flat. At $1 / 3$ of the height the transition between both profiles is sudden, it represents the so-called "neutral level". A very similar temperature profile was observed by Azzouz et al. (1993) for a $13000 \mathrm{~m}^{3}$ cold room over a door opening time of $52 \mathrm{~s}$.

- At $\mathrm{t}=20 \mathrm{~s}$ : the temperature profile remains the same as previously above the neutral level. Below it, the temperature has increased but keeps a flat shape around $278 \mathrm{~K}$. The outside air that flows into the truck body to balance the inside air flowing out, mixes with the inside air that stays in the truck.

In that region the numerical result gives a temperature $8 \mathrm{~K}$ higher than the experimental data. Close to the floor, the temperature does not change and keeps its initial value.

- At $\mathrm{t}=40 \mathrm{~s}$ : the temperature exhibits an increasing profile along the door opening from $273 \mathrm{~K}$ close to the floor to $293 \mathrm{~K}$ at the top of the opening. The neutral level is not clearly distinguishable as the discontinuity of the profile at the neutral level is not obviously visible. In the lower part, the experimental temperature is only $20 \mathrm{~K}$ below the ambient. The model agrees with the experimental profile except close to the wall.

- At $\mathrm{t}=60 \mathrm{~s}$ : the temperature profile is almost the same as the one at $40 \mathrm{~s}$; the quasi-steady state has been reached. The inflow is cooled down by the wall and leaves the truck body on average $10 \mathrm{~K}$ below the ambient.

The temperature at the lowest point of the opening remains at the initial value during a period of time of $20 \mathrm{~s}$ before it starts increasing. Interestingly this characteristic time has already been observed and described as the time required for most of the air initially present to flow out of the insulated body.

The experimental results are well predicted by the model except during the transition phase (15 - 25s) between the unsteady flow and the quasi-steady flow. This corresponds also to the time where the model requires a finer time step to converge.

\subsection{Infiltration velocity}

Given the characteristics of the anemometers used during the experiments, the experimental velocity profile could be compared directly to the magnitude of the predicted velocity vectors. This comparison is provided in Figure 9 for the full opening for times up to $t=60 \mathrm{~s}$.

- At $\mathrm{t}=10 \mathrm{~s}$ : the experimental and numerical profiles are in good agreement and show that the velocity magnitude reaches two peaks at the ceiling $(0.8 \mathrm{~m} / \mathrm{s})$ and at the floor $(1.5 \mathrm{~m} / \mathrm{s})$. The velocity is minimum at $1 / 3$ of the height which clearly corresponds to the neutral level. The velocity profile typically characterizes the renewal of the air inside a cavity. Azzouz et al. (1993) obtained almost the same velocity peaks for a slightly higher temperature gradient $(45 \mathrm{~K})$.

- At $\mathrm{t}=20 \mathrm{~s}$ : the velocity profile becomes flat in the upper part of the doorway and reaches $0.4 \mathrm{~m} / \mathrm{s}$. This profile may be due to the suction of the external air into the truck body occurring after the renewal of the inside air. The neutral point remains at the same height. The maximum velocity magnitude in the lower part decreases to $1 \mathrm{~m} / \mathrm{s}$ for the experimental result and to $0.7 \mathrm{~m} / \mathrm{s}$ for the model. 
- At $\mathrm{t}=40 \mathrm{~s}$ : the velocity in the upper part of the doorway is reduced to $0.2 \mathrm{~m} / \mathrm{s}$. Experiments and predictions are in good agreement in that region. In the lower part the maximum experimental velocity is reduced to $0.6 \mathrm{~m} / \mathrm{s}$ and is underpredicted by the model. 


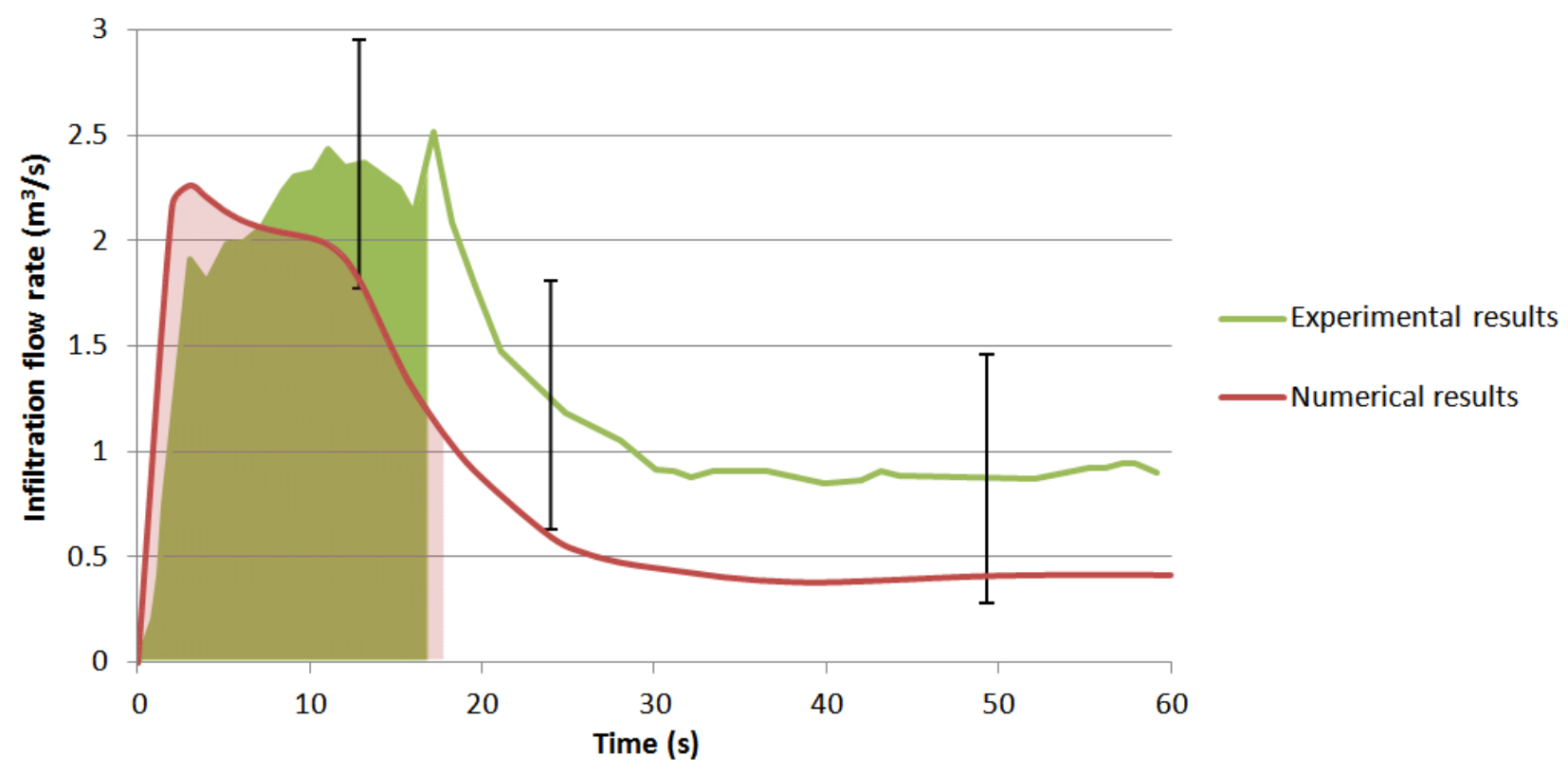

Figure 6: Evolution of the infiltration flow rate for the baseline case.

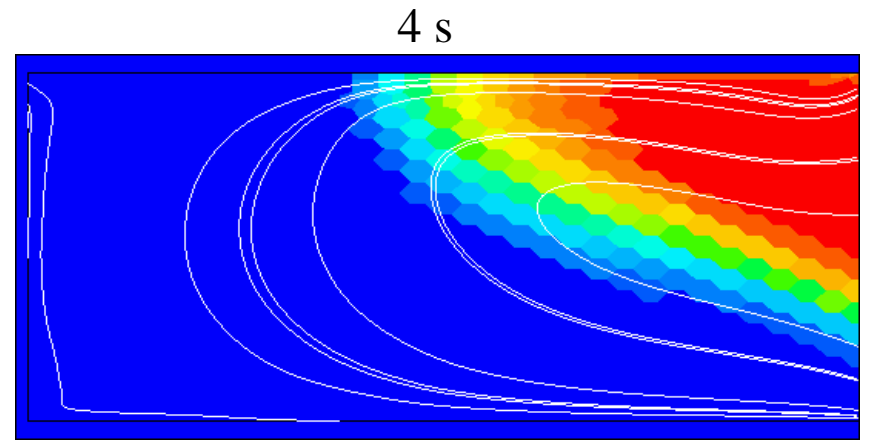

$10 \mathrm{~s}$

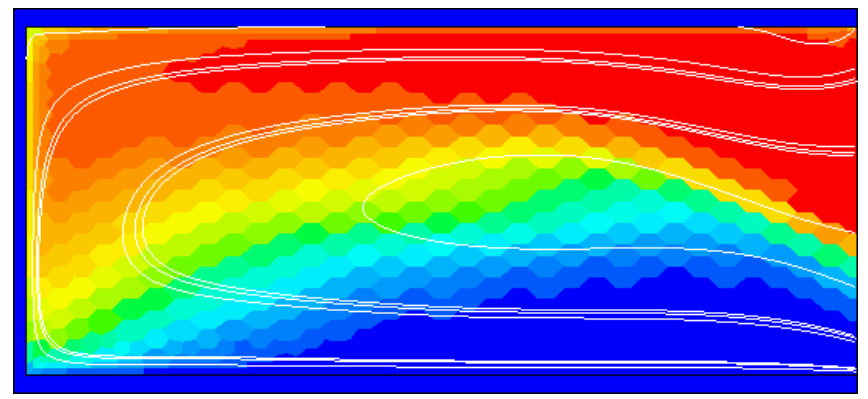

$15 \mathrm{~s}$

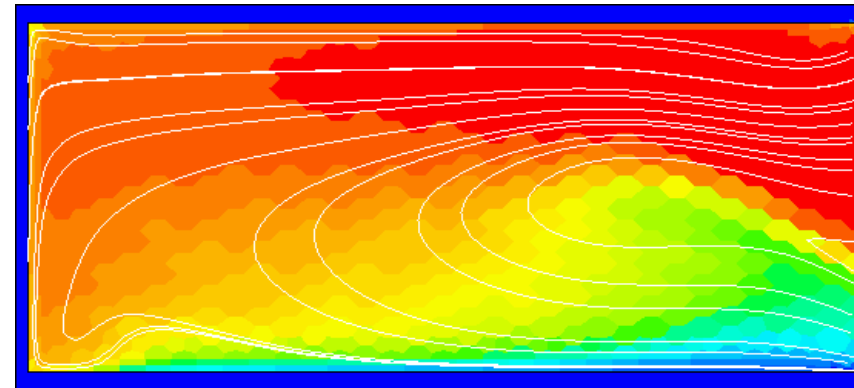

253.00

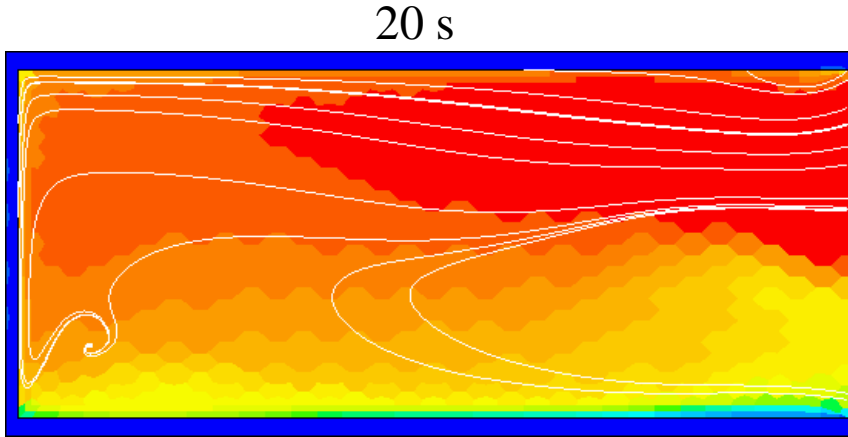

$40 \mathrm{~s}$

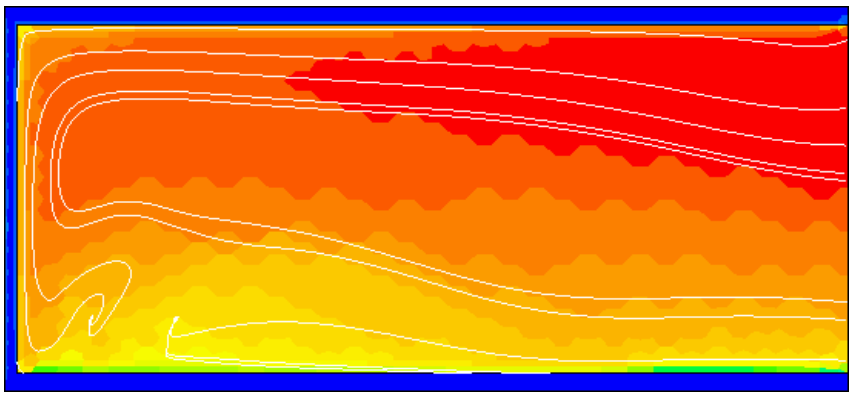

$60 \mathrm{~s}$

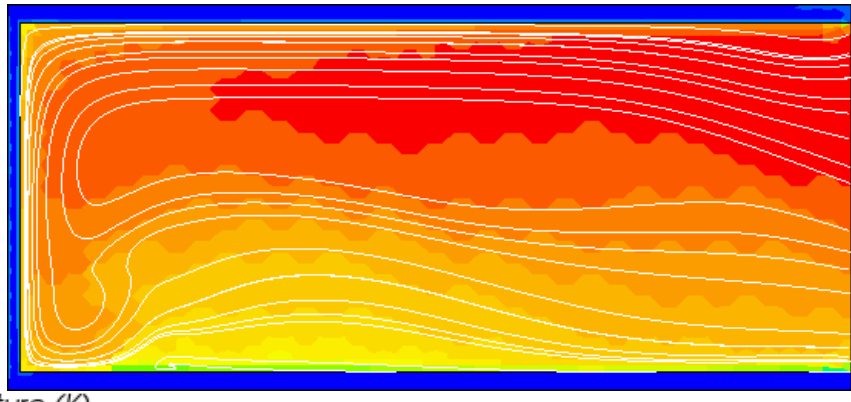

293.00

Figure 7: Numerical temperature fields and streamlines in the symmetry plane for the baseline case. 
$10 \mathrm{~s}$

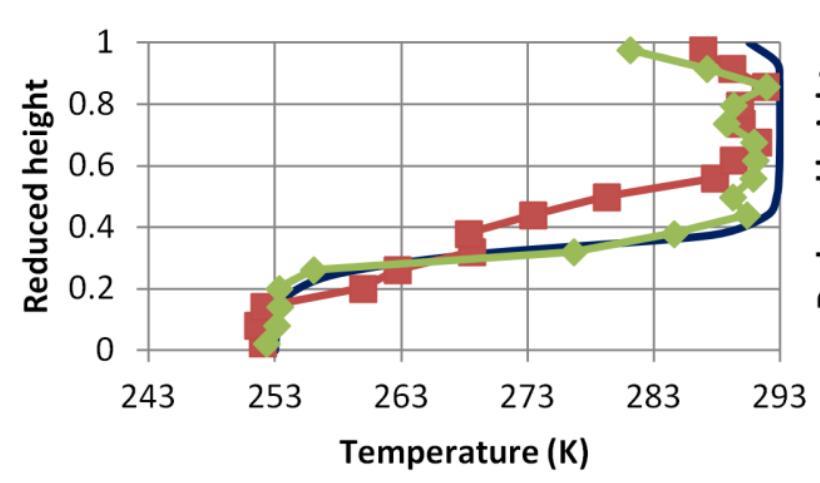

$20 \mathrm{~s}$

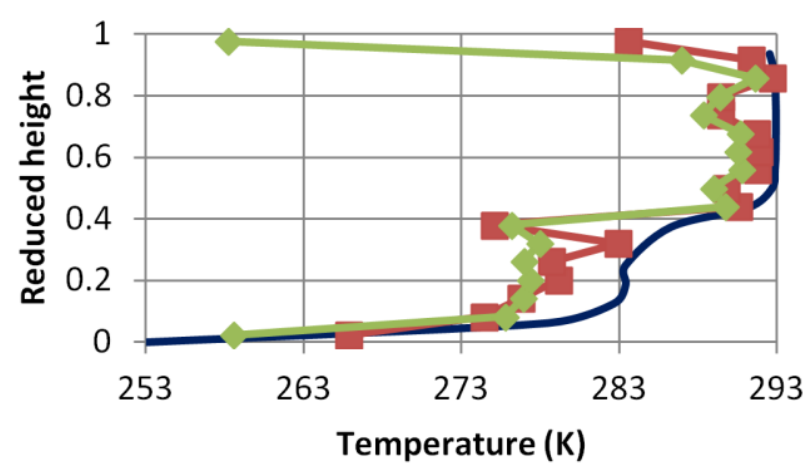

$40 \mathrm{~s}$

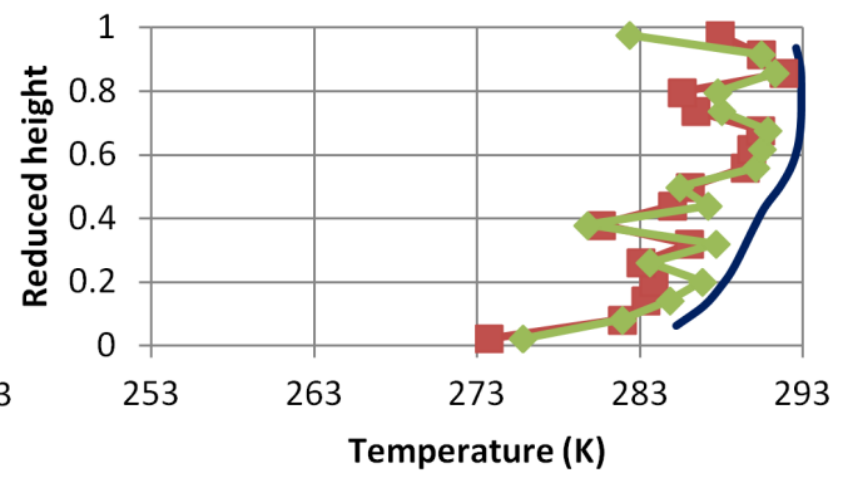

$60 \mathrm{~s}$

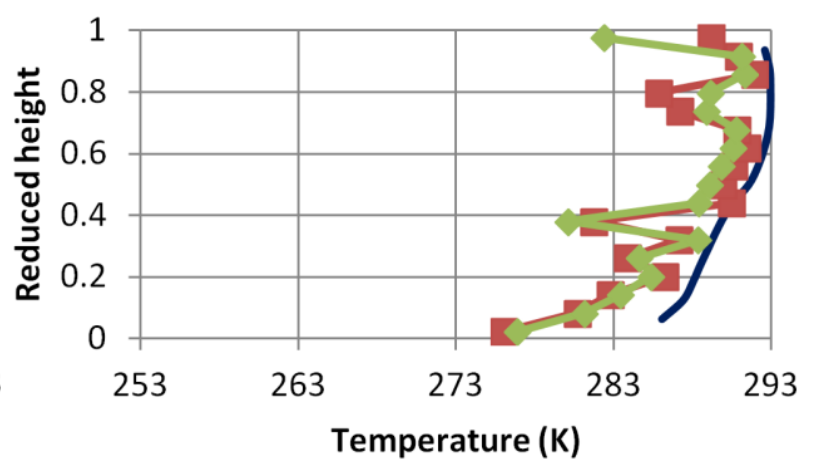

Figure 8: Temperature in the symmetry plane of the doorway for the baseline.

\section{$\longrightarrow$ Exp P3 N1 שExp P3 N2 Model}

- At $\mathrm{t}=60 \mathrm{~s}$ : the velocity profile is almost the same as that at $40 \mathrm{~s}$; the quasi-steady state has been reached. The velocity magnitude is slightly greater than that at $40 \mathrm{~s}$, due to the natural convection flow which is developing close to the walls.

The model agrees with the experimental profile in the upper part of the opening. However the velocity magnitude in the lower part is clearly underpredicted, except $10 \mathrm{~s}$ after the door opening. Temperature and velocity profiles allow to conclude that the neutral level is constant at about $1 / 3$ of the height over the first $60 \mathrm{~s}$ of the opening time, as observed by Azzouz et al. (1993).

\subsection{Infiltration heat load}

During the door opening, the inside air volume is mainly warmed up due to the sensible heat load related to the mass interchange. However, it is difficult to quantify the latent heat that actually applies to the air volume when water condenses. Indeed, from the inside-outside mass balance it is possible to estimate the water mass flow rate that enters the truck body. However, part of this water mass could either (i) condenses over the body inner wall, or (ii) remains under vapour state and be stored in the air volume due to its temperature increase, or even (iii) condenses under the shape of droplets releasing heat to the air if $100 \%$ relative humidity is reached inside the body. For example, for $20{ }^{\circ} \mathrm{C}$ outside temperature and $-20{ }^{\circ} \mathrm{C}$ inside temperature, the increase of the inside air temperature is sufficient to potentially absorb all the water vapour mass flowing through the doorway. This is not the case for the experiment with $5{ }^{\circ} \mathrm{C}$ outside temperature. To verify if some latent heat had actually warmed the inside air volume, the energy received by the air ( $\left.Q_{\text {air }}^{\circ}\right)$ was compared to the total and sensible infiltration load $\left(Q_{\text {tot }}^{*}\right.$ and $\left(Q_{1} s\right)$ ), as illustrated in Figure 10 for a typical case. The energy received by the air $\left(Q_{\text {air }}^{*}\right)$ is obtained from an energy balance for the internal air over the opening time:

$Q_{\text {air }}^{\cdot}=\dot{V}\left[\left(C_{w} C_{p_{w}}+C_{d a} C_{p_{d a}}\right) T_{i}-\left(C_{w}^{0} C_{p_{w}}+C_{d a}^{0} C_{p_{d a}}\right) T_{i}^{0}\right]$

where $T_{\tilde{i}}$ is experimentally measured at the door closing. 
The sensible infiltration load $\left(\dot{Q}_{s}\right)$ is obtained by integrating the heat flux over the door area during the opening time, taking only into account the dry air:

$\dot{Q}_{s}=\iiint u C_{d a} \boldsymbol{h}_{d a} d A_{a y} d t$

The total heat load $Q_{\text {tot }}^{*}$ is obtained by integrating the heat load taking into account the dry air and the water vapor assuming that all the water vapor entering condenses:

$Q_{\text {tot }}^{*}=\iiint\left(u C_{d a} \boldsymbol{h}_{d a}+\frac{u+|u|}{2} C_{w} \boldsymbol{h}_{w}\right) d A_{a p} d t$

Noting that $\frac{u+|u|}{2}= \begin{cases}0 & \text { if } u<0 \\ u & \text { if } u>0\end{cases}$

For all the temperature conditions, $Q_{\text {air }}^{*}$ values were found to be close to $\dot{Q}_{s}$, which tends to confirm that no heat of condensation was transmitted to the inside air volume. Thus, in the present paper, the latent heat load analysis and prediction is not considered.

More precisely, as observed for the instance of Figure 10, it is seen that during a first period (20 s for this example) the heat received by the inside air volume $\left(\boldsymbol{Q}_{\text {air }}^{*}\right)$ roughly corresponds but is slightly lower than the sensible heat load $\left(\dot{Q}_{s}\right)$. The smaller value of $\dot{Q}_{\text {air }}^{*}$ is probably due to the heat exchange occurring between the inside air and the body cold walls. Then, after this time period, the inside air temperature reaches a ceiling and remains quasi-unchanged which implies that no heat is anymore received by the body air volume. Thus, the infiltration heat load must apply mostly to the body walls. As a consequence, two successive time periods with two different physical phenomena should be considered. During a first short period (found to be 30 to $40 \mathrm{~s}$ for the full aperture or 80 to $100 \mathrm{~s}$ for a $1 / 3$ aperture ratio), heat and mass exchanges occur directly between the outside and inside air volumes. This first stage should be called buoyancy driven flow in that sense that it is driven by density differences between two volumes of air. This infiltration phenomenon is highly unsteady due to the very high heat flow rate and low thermal inertia of the inside air volume. This implies that the volume flow rate reaches a maximum value and then decays (Figure 6). The second period is dominated by a direct heat exchange between the outside air and the body inner wall. In this case, we have a boundary layer flow. This is a quasi-steady-state natural convection phenomenon involving lower heat flow rates and a higher thermal inertia of the body walls (four times higher than the inside air volume in the present case).

$10 \mathrm{~s}$
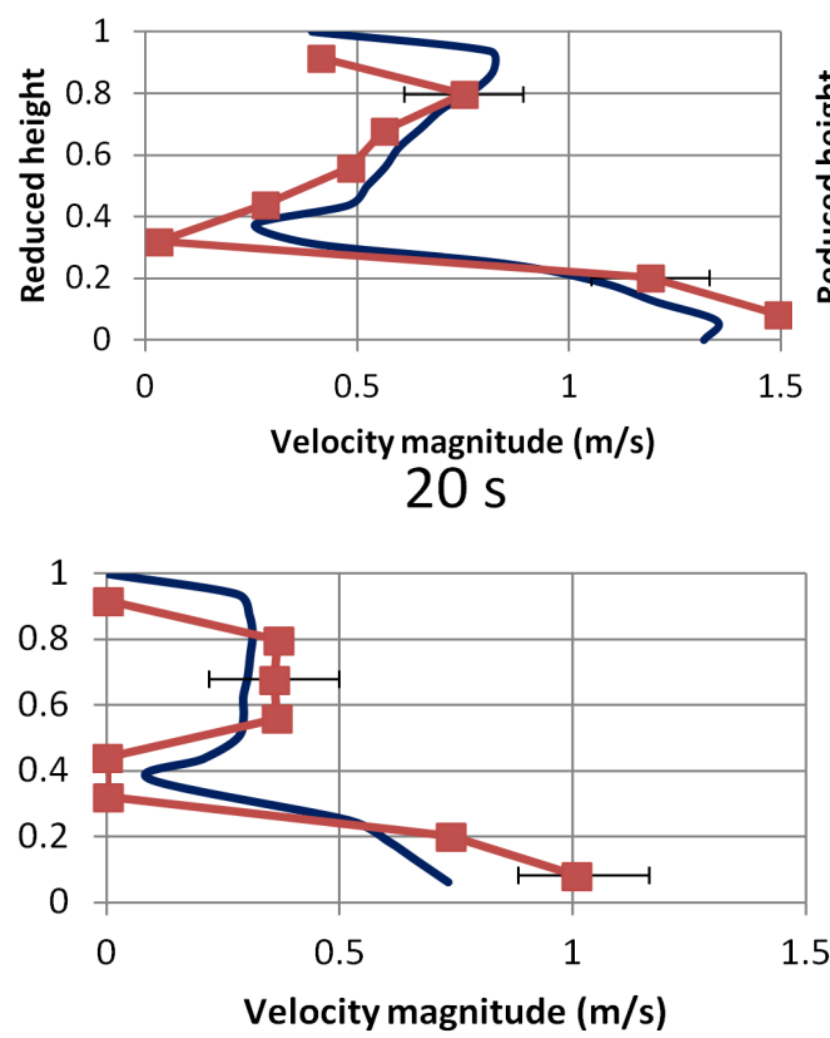

$40 \mathrm{~s}$
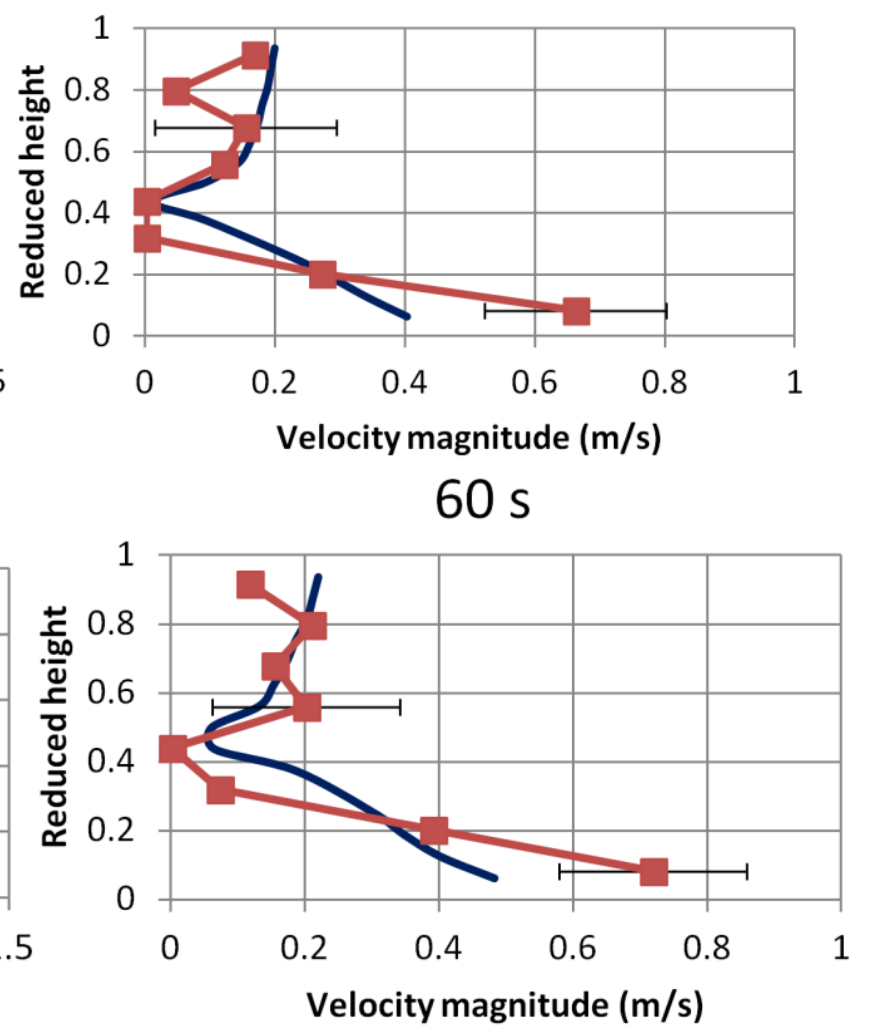
Figure 9: Velocity profiles in the symmetry plane of the doorway for the baseline.

$\rightarrow$ Exp P3 N1 Model

\subsection{D infiltration flow in the door plane}

Numerical simulation can help reveal features of the flow that cannot be detected experimentally, among which 3D features of the flows. Temperature and velocity fields are depicted in the door cross section plane for the dates $t=10 \mathrm{~s}$ and $\mathrm{t}=60 \mathrm{~s}$ after the door opening and for the full aperture (Figure 11). The temperature field at the date $t=10 \mathrm{~s}$ and $\mathrm{t}=60 \mathrm{~s}$ does not depend much on the lateral position. The vertical wall located at the left and at the right of the field do not impact to much the temperature On the contrary, the longitudinal velocity fields strongly depend on the lateral position. In the upper corner a more important velocity, especially at the date $\mathrm{t}=60 \mathrm{~s}$ is observed. The phenomenon in the corner is probably due to a double Coanda effect occurring between the vertical wall and the ceiling of the body. Moreover in the lower part of the opening a high velocity is observed at the center of the opening. This velocity increase is due to the natural convection occurring on the vertical wall inside the truck body, driving the air down to the floor and along the floor to the doorway center. The velocity field is therefore impacted by the vertical wall.

\subsection{Influence of the temperature conditions}

The effect of the initial outside and inside temperatures is depicted in Figure 12 from a set of experimental results that show the infiltration volume flow rate as a function of time. Two periods of time are shown: the first $40 \mathrm{~s}$ corresponds to the buoyancy driven flow and a longer period of 400 to $600 \mathrm{~s}$ corresponds to the boundary layer flow. Regarding the points of maximal flow rate, it is verified that the values increase with the initial temperature difference, i.e. the initial density difference. Thereby, curves corresponding to a similar temperature difference $(20$ and $40 \mathrm{~K})$ nearly reach the same maximal point; the $60 \mathrm{~K}$ temperature difference curve being the highest. This order is no more respected during the second period (after few minutes). As indicated in Figure 12, the volume flow rate is then much more influenced by the initial temperature of the body, i.e. the walls temperature, than influenced by the temperature difference. Thus, flow rates for the inside temperature of $273 \mathrm{~K}$ are lower than for the inside temperature of $253 \mathrm{~K}$.

However, the sensible heat flow rates observed in this second period of time (depicted in Figure 13) still increase with the temperature difference, which is related to the driving phenomenon that was identified previously, i.e. natural convection. The volume flow rate is not necessarily directly correlated with the heat flow rate for the boundary layer flow, since the difference of temperature between the inlet and the outlet flows depends on the heat exchange with the wall. Still, the correlation between volume and heat flow rate remains valid for the buoyancy driven flow.

The influence of two initial temperature conditions on experimental and predicted temperature and velocity profiles, for the full opening are compared on Figure 14. The external temperature is kept constant $\left(\mathrm{T}_{\mathrm{o}}=293 \mathrm{~K}\right)$. Temperatures are presented in a dimensionless form:

$T^{\prime}=\frac{T-T_{i}^{0}}{T_{o}-T_{i}^{0}}$

Experimental dimensionless temperature profiles do not depend on the initial temperature for times $t=10 \mathrm{~s}$, $\mathrm{t}=40 \mathrm{~s}$ and $\mathrm{t}=60 \mathrm{~s}$.

However at $t=20 \mathrm{~s}$, for $\mathrm{T}_{\mathrm{i}}^{0}=273 \mathrm{~K}$, the temperature in the lower part of the opening is much lower than for the base line case $\left(\mathrm{T}_{\mathrm{i}}^{0}=253 \mathrm{~K}\right)$. All the internal air is not completely renewed until a time comprised between $\mathrm{t}=20 \mathrm{~s}$ to $\mathrm{t}=40 \mathrm{~s}$.

The transition between buoyancy driven and boundary layer flow is actually delayed compared to the baseline case. The model accurately predicts this delay even if the transition of the flow is not well simulated ( $c f$. section 4.3). The delay is due to the smaller density difference which reduces the driving force of the infiltration. The delayed buoyancy driven flow has no influence on the temperature profile after the transition to the boundary layer flow.

Dimensionless experimental temperature profiles also show some abrupt and localized decreases at the same locations for both initial temperatures. These phenomena can clearly be distinguished for $t=40 \mathrm{~s}$ and $\mathrm{t}=60 \mathrm{~s}$. They may be due to stationary recirculation cells occurring at the door plane that cannot be predicted by the model.

As observed with the flow rate on Figure 12, the velocity is larger for $\mathrm{T}_{\mathrm{i}}^{0}=253 \mathrm{~K}$ than for $\mathrm{T}_{\mathrm{i}}^{0}=273 \mathrm{~K}$, except around $\mathrm{t}=20 \mathrm{~s}$. At this time and for $\mathrm{T}_{\mathrm{i}}^{0}=273 \mathrm{~K}$, the internal air is not completely renewed and the density 
difference is still driving the flow out whereas for $T_{i}^{0}=253 \mathrm{~K}$, the boundary layer flow has already started. Numerical profiles are in good agreement with both experimental trends. The model is believed to be valid for the $\mathrm{T}_{\mathrm{i}}^{0}=273 \mathrm{~K}$ case. 


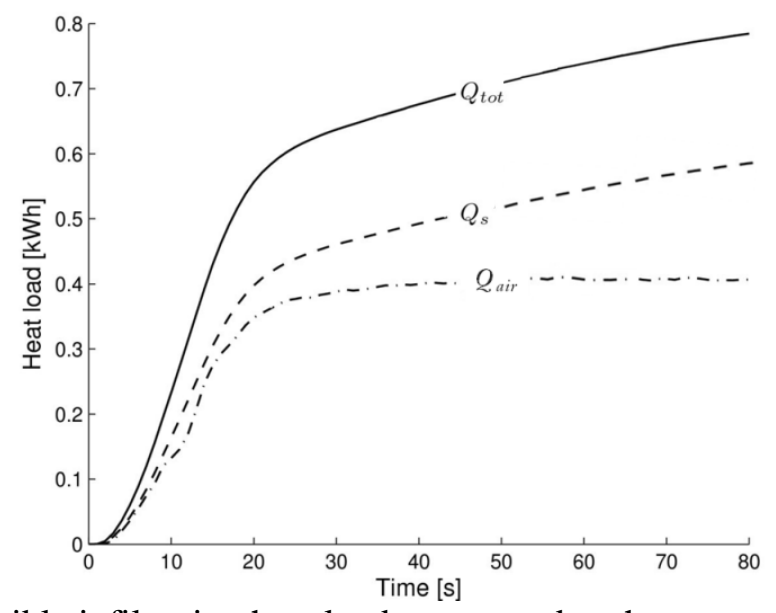

Figure 10: Total and sensible infiltration heat loads compared to the energy received by the inside air volume, for the baseline case and full aperture.

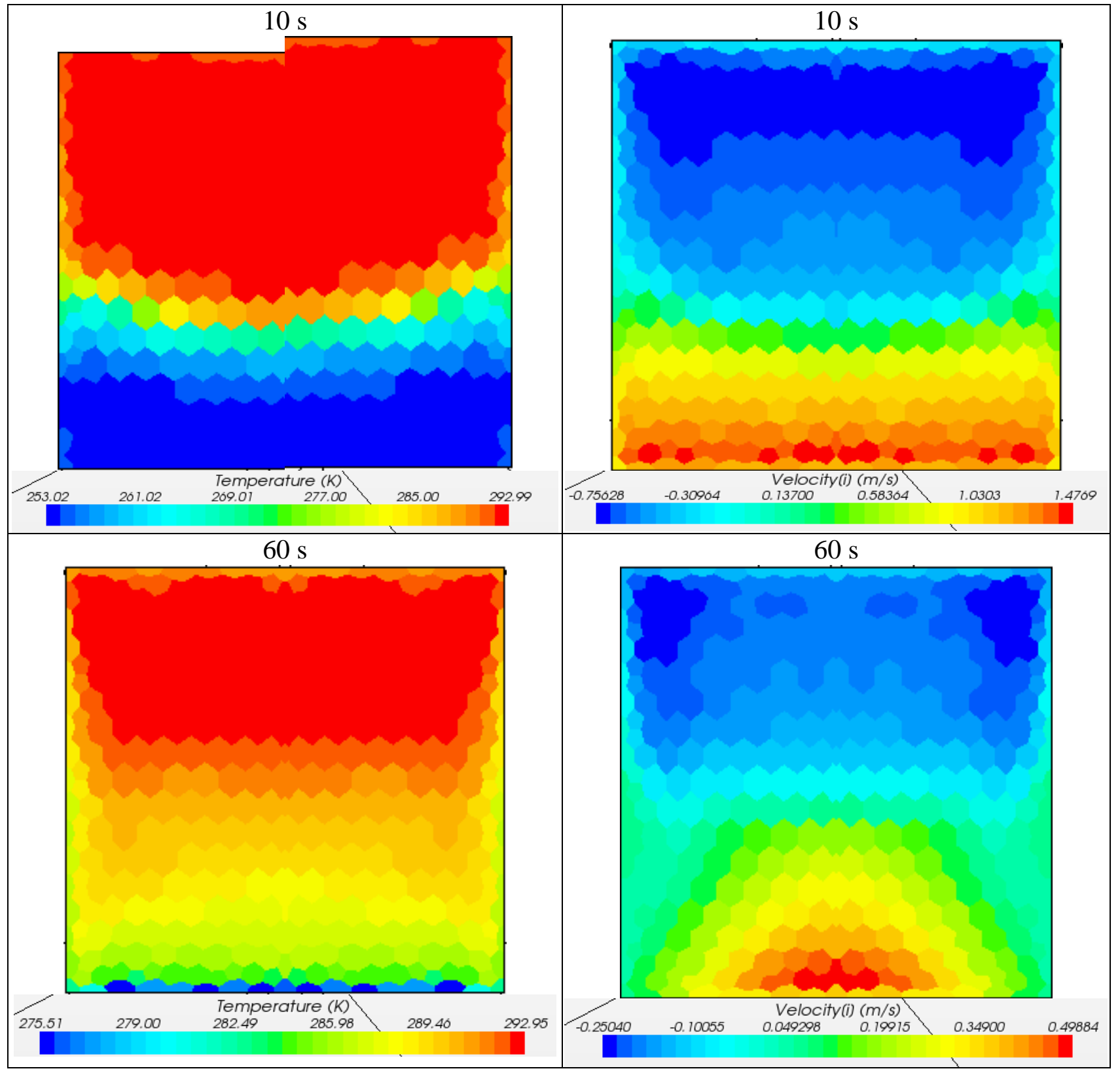


Figure 11: Temperature and longitudinal velocity component fields in the doorway cross section 10 and $60 \mathrm{~s}$ after door opening. 

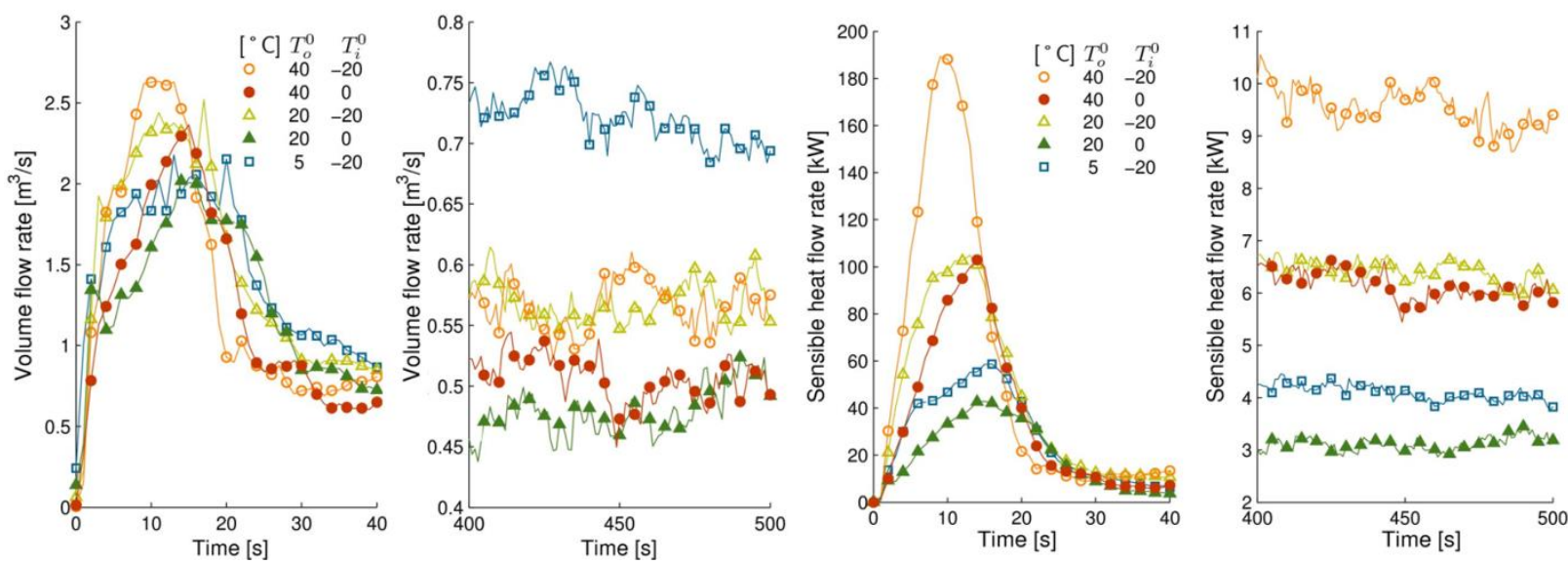

Figure 12: Effect of the temperature conditions on the volume flow rate for the full door opening

(calculated value based on experiments).

Figure 13: Effect of the temperature conditions on the heat flow rate for the full door opening (calculated value based on experiments).

\subsection{Influence of the aperture ratio}

The effect of the aperture ratio was not modelled by CFD but it was investigated experimentally. Figure 15 shows the experimental volume flow rate per opening area $\left(\dot{V} / A_{a p}\right)$ as a function of time. It is observed that roughly the same maximal volumetric flux is attained independently of the aperture ratio. Hence, the volume flux rate seems dimly affected by the surface of the opening during the buoyancy driven flow. However, a discrepancy is seen in the decreasing rate and stabilisation value of the volumetric flux. Full and $2 / 3$ openings have very similar curves, whereas the $1 / 3$ lateral aperture gives a different trend. Note that data similar to those of the latter case can also be obtained with the $1 / 3$ central aperture for the same temperature difference $\left(T_{o}^{0}=40{ }^{\circ} \mathrm{C}\right.$ and $\left.T_{i}^{0}=0{ }^{\circ} \mathrm{C}\right)$. The deviation generated by large and small apertures can be explained as follows. As the aperture ratio diminishes, the infiltration heat flow rate becomes smaller. Accordingly, the inner temperature increases more slowly and the decrease of the volume flow rate is more gradual. Considering that the body inner wall area is constant, then, to extract the same energy, a smaller aperture ratio will induced a higher volume flow rate per unit of opening area, as well as a lower inside temperature or driving force.

Another discrepancy between large and small openings refers to the velocity profile, as indicated in Figure 16. Indeed for the total opening (Figure 16 a), the hot air enters the body with a velocity that does not change much with height, whereas the cold air flows outside with a velocity constantly increasing when moving away from the neutral level point. On the contrary, for a 1/3 aperture ratio (Figure $16 \mathrm{~b}$ ), it is observed that the neutral level is a bit higher and that the velocity profile is more symmetrical. Moreover, the velocities stick to a relatively high level during a longer time span.

A further comparison is depicted in Figure 17 where the time period requested to empty the body from the cold air $\left(\Delta t_{\text {empty }}\right)$ is reported for different aperture ratios as a function of the initial temperature difference between the inside and outside air. On one hand, results are presented based on the measured temperature. $\Delta t_{\text {empty }}$ is obtained when the averaged inside temperature is equal to the outside temperature. On the other hand results are presented based on the volume flow rate. $\Delta t_{\text {empty }}$ is then obtained when the integral of the flow rate is equal to the volume of the body. As expected, a larger temperature difference generally corresponds to a smaller $\Delta t_{\text {empty }}$ due to a larger driving force (density difference). In addition, comparing full and $1 / 3$ apertures, it comes out that the cold air replacement time is roughly inversely proportional to the aperture ratio. However, for the 1/3 aperture ratios, a clear discrepancy appears between the replacement time deduced from the temperatures and the one calculated from the volume flow rate. Obviously, a phenomenon of mixing also enters into account that slows down the evacuation of the cold air, namely for a small opening, i.e. a small flow rate compared to the body volume. Another discrepancy may also be observed when comparing the central $1 / 3$ aperture ratio with the lateral $1 / 3$ ratio.

According to the reasoning of section 4.6 which describe the double coanda effect occurring at the corner, it could be expected that for the $1 / 3$ lateral aperture a smaller time period would be required to replace the internal air compared to the $1 / 3$ central aperture. In the first case the coanda effect would drive the flow out of the body, whereas for the central aperture no coanda effect would occur. However the contrary is 
observed. The 3D effects occurring for the full aperture may therefore not be extended to different aperture ratios and have to be studied more deeply.

\section{A SIMPLE HEAT LOAD PREDICTION METHOD}

In order to correctly predict the infiltration heat load during the door opening of a truck body, the two phenomena that were identified and discussed previously should be taken into account: (i) the unsteady buoyancy driven flow appearing just after the door opening and decaying after a short period; and then (ii) the quasi-steady-state boundary layer flow lasting a longer time. Two different approaches were used to model these heat exchange mechanisms.

\subsection{Boundary layer flow}

Boundary layer flow is equivalent to natural convection over a surface. As a consequence, a classical expression (Incropera et al. 2001) standing for this heat transfer mechanism was adopted as a basis, that is:

$\overline{N u_{H}}=C R a_{H}^{n}$,

where $C$ and $n$ are two coefficients that depend on the surface geometry and direction. Moreover, in the present case, the height $(\mathrm{H})$ was chosen as the characteristic length. The mean Nusselt number over the inner surface $(\mathrm{Nu})$ is calculated as:

$\overline{N u_{H}}=\frac{Q_{s}}{\left(T_{o}-T_{W}\right) A_{W}} \frac{H}{\lambda}$,

where $T_{o}$ is the temperature of the air outside of the truck body, $T_{W}$ is the mean inner wall temperature weighted by the area of each panel of the body, $A_{W}$ is the total surface area of the inner wall, and $\lambda$ is the thermal conductivity of air. Furthermore, the Rayleigh number $(R a)$ takes the following form:

$R a_{H}=\frac{g \beta \Delta T H^{3}}{\alpha v}$,

where $\alpha$ and $v$ are the thermal diffusivity and kinematic viscosity of air. Moreover, under the assumption of a perfect gas behavior, the air relative expansion can be written as:

$\beta \Delta T=\frac{T_{o}-T_{w}}{0.5\left(T_{o}+T_{w}\right)}$.

Note that all the properties were calculated for dry air at the film temperature (mean of $T_{o}$ and $T_{w}$ ).

Eq. (12) was then fitted to the experimental heat flow rates calculated between 200 and $600 \mathrm{~s}$. A best accordance was found with $n=1 / 3$. Different $C$ values were found depending of the aperture ratio: $C=0.139$ for the full aperture; $C=0.126$ for the $2 / 3$ aperture; $C=0.116$ for the $1 / 3$ central aperture; and $C=0.118$ for the 1/3 lateral aperture. A comparison between experimental and predicted heat flow rates is shown in Figure 18. Despite the simplicity of the suggested approach, a quite good agreement was found with more than $94 \%$ of the data predicted within $\pm 10 \%$. For the whole experimental conditions, we have: $2.10^{10}<R a_{H}<9.10^{10}$, which characterizes turbulent flows. Accordingly, the coefficients $C$ and $n$ in the present study are very close to those of a classically expression (Mc Adams, 1961) used for natural convection over a vertical plate, in turbulent conditions:

$\overline{N u_{H}}=0.13 R a_{H}^{1 / 3}$

\subsection{Buoyancy driven flow}

The equations describing the buoyancy driven flow were derived from the ideal steady-state flow model (e.g. Brown and Solvason, 1963), but two terms standing for mass inertia and thermal inertia were added as explained in the following. The truck body is represented as a rectangular cavity depicted in Figure 19. This cavity has a given height $(H)$, length $(L)$, width $(W)$ and inner volume $(V)$. The doorway has a flow crosssection $\left(A_{a p}\right)$ corresponding to a given aperture width $\left(W_{a p}\right)$.

For the sake of simplicity, it is assumed that the neutral level is located at the middle of the opening height $(H / 2)$ where the pressure is equal to $P_{a t m}$. Then, the inside and outside pressures are known from the height (z) relative to the neutral point (Roy Munson et al. 2012):

$P_{i}=P_{a t m}-\rho_{i} g z$;

$P_{o}=P_{a t m}-\rho_{o} g z$ 
where $\rho_{i}$ and $\rho_{o}$ are respectively the inside and outside densities. 
$10 \mathrm{~s}$

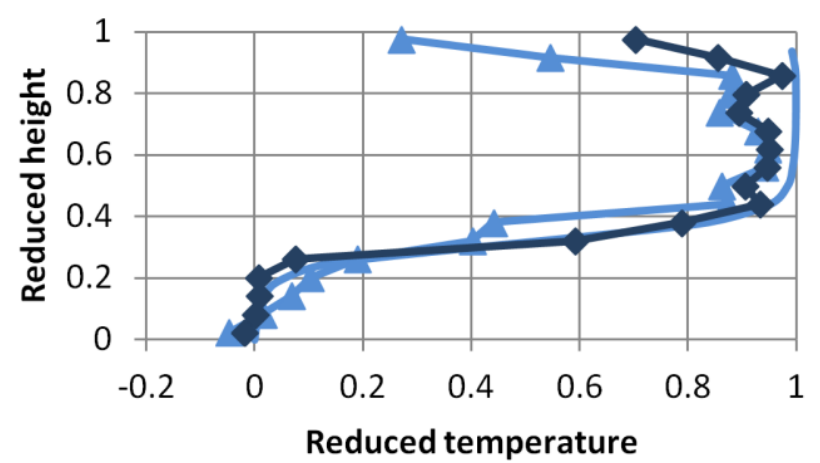

$20 \mathrm{~s}$

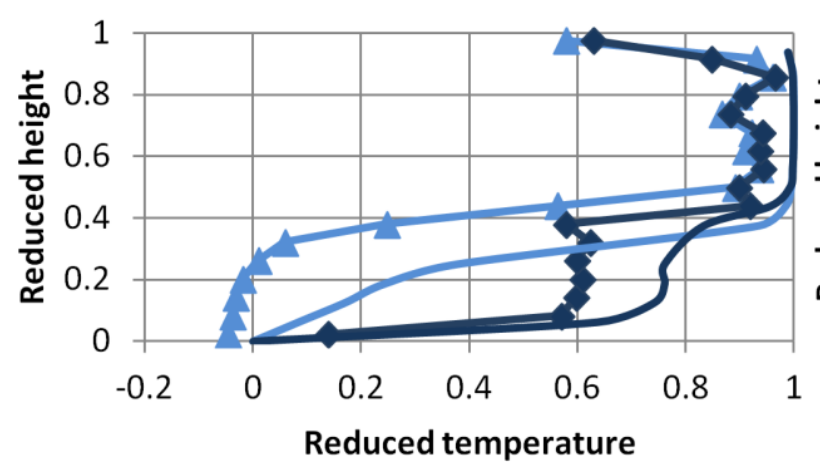

$40 \mathrm{~s}$

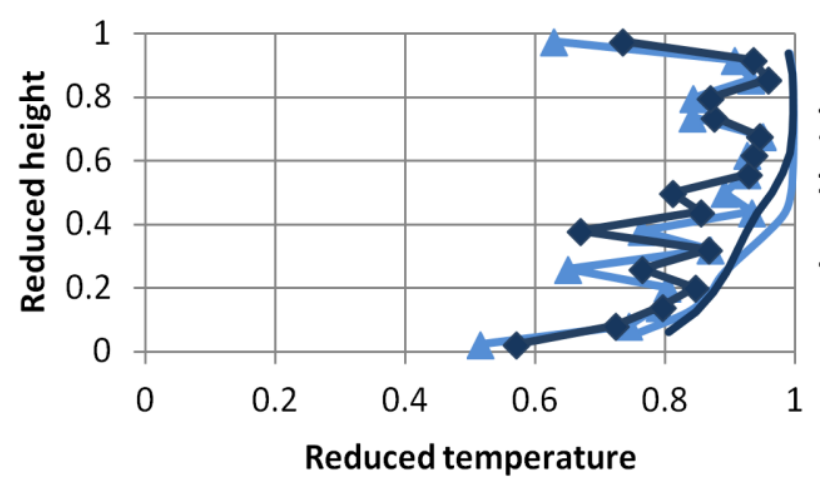

$60 \mathrm{~s}$

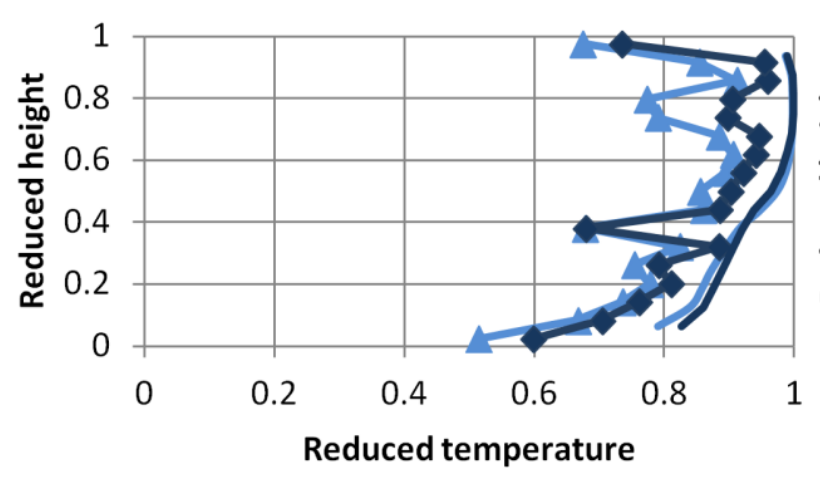

$10 \mathrm{~s}$

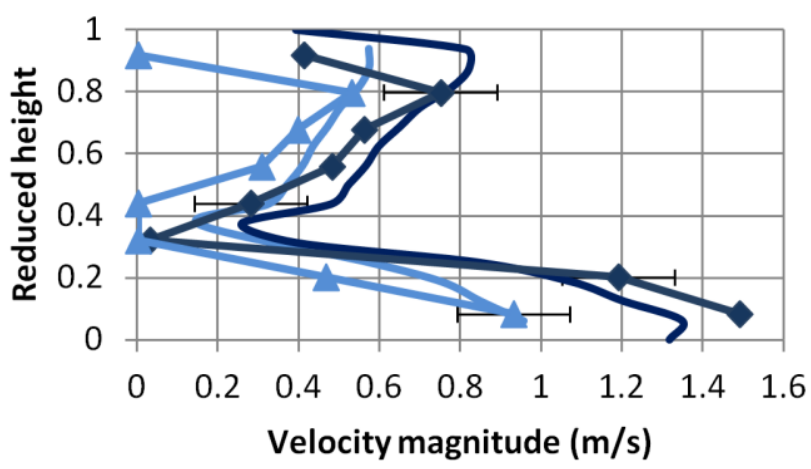

$20 \mathrm{~s}$

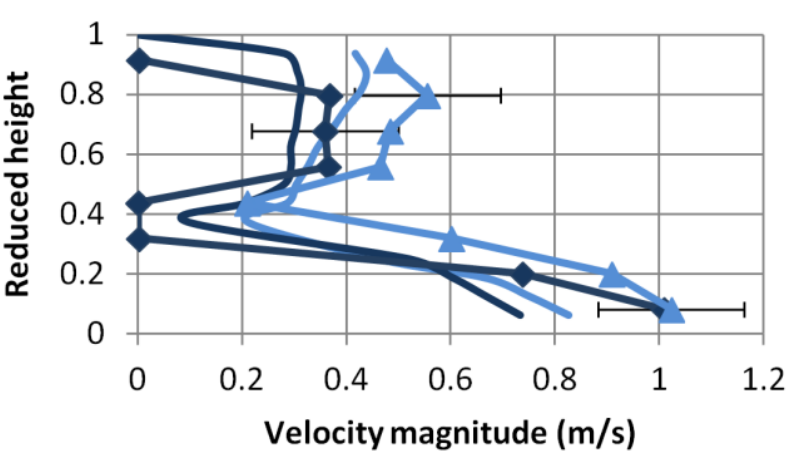

$40 \mathrm{~s}$

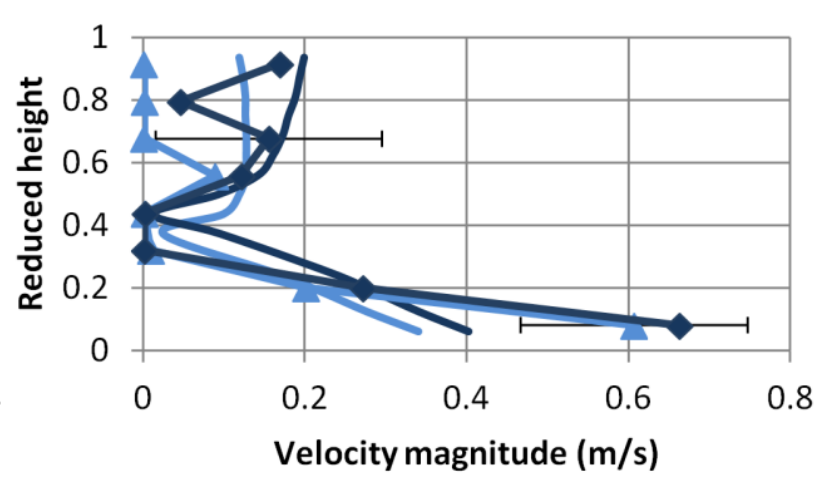

$60 \mathrm{~s}$

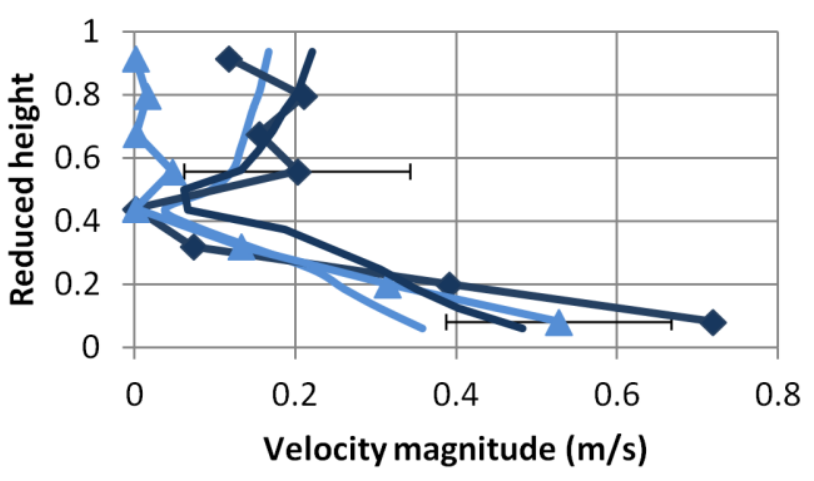

Figure 14: Influence of initial temperature on temperature and velocity profiles in the symmetry plane. Experiences: $\leftarrow \mathrm{T}=273 \mathrm{~K} \rightarrow \mathrm{T} \mathrm{i}=253 \mathrm{~K}$, Model: $\longrightarrow \mathrm{Ti}=273 \mathrm{~K} \longrightarrow \mathrm{T}=253 \mathrm{~K}$. 


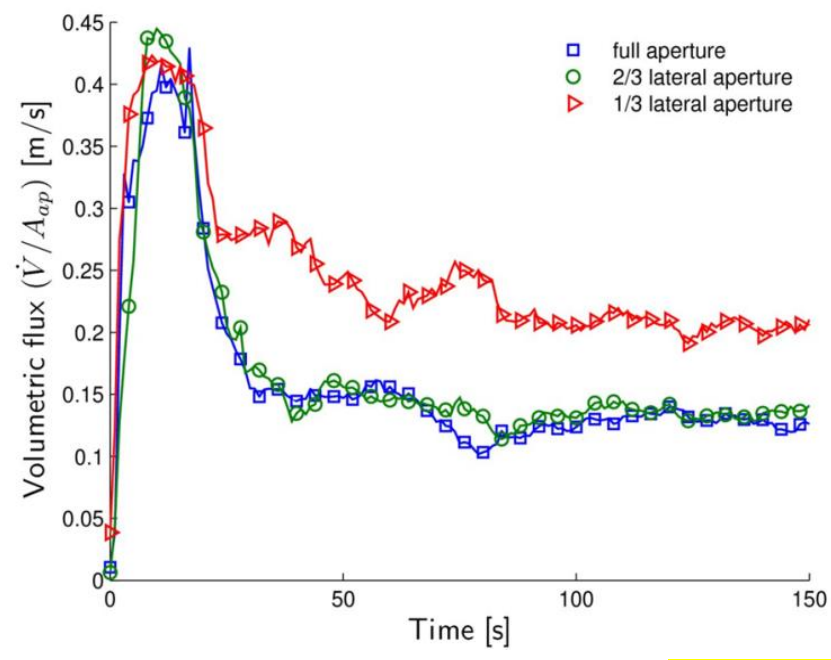

Figure 15: Influence of the aperture ratio on the volumetric flux.

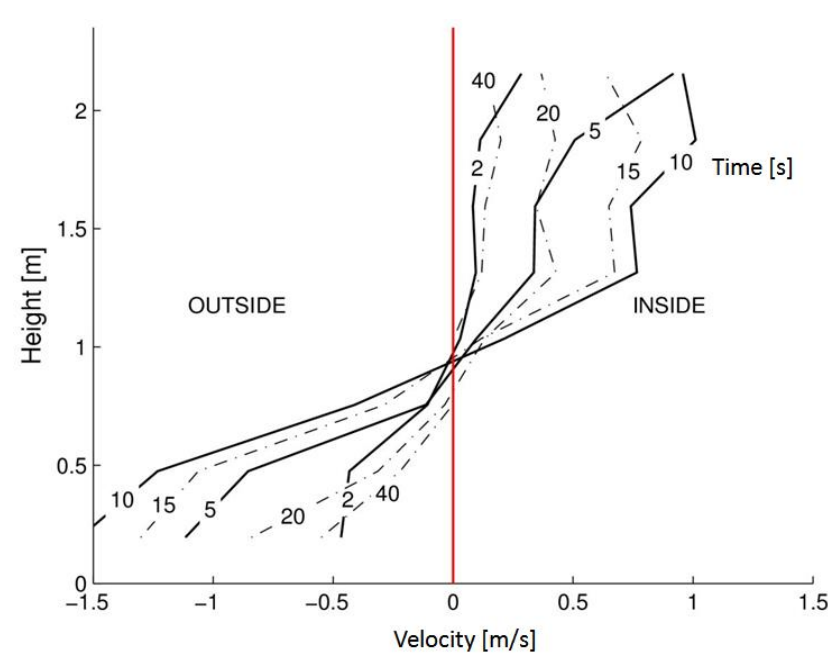

(a)

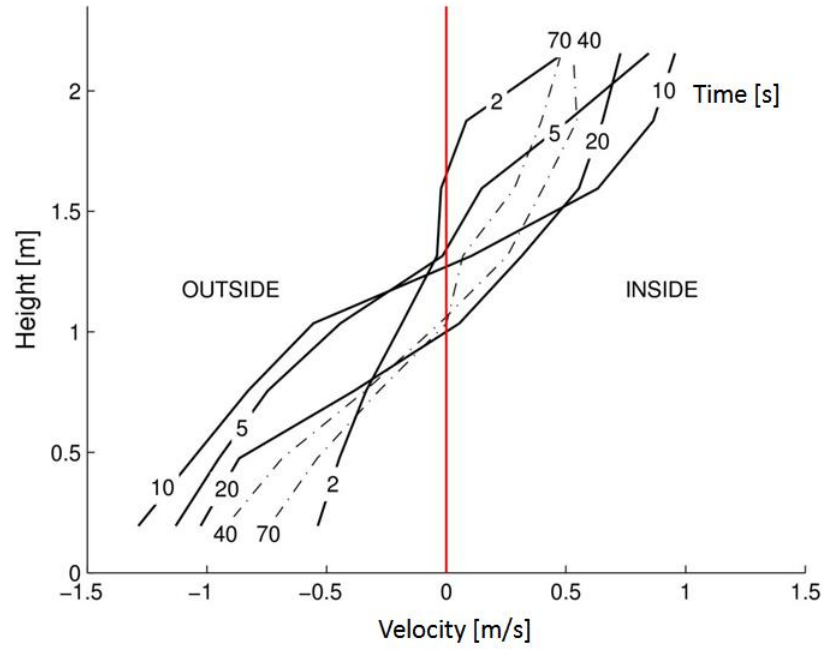

(b)

Figure 16: Evolution of the velocity profile with time for $T_{i}^{0}=-20^{\circ} \mathrm{C}$ and $T_{0}^{0}=40^{\circ} \mathrm{C}$ :

(a) full aperture; (b) $1 / 3$ central aperture.

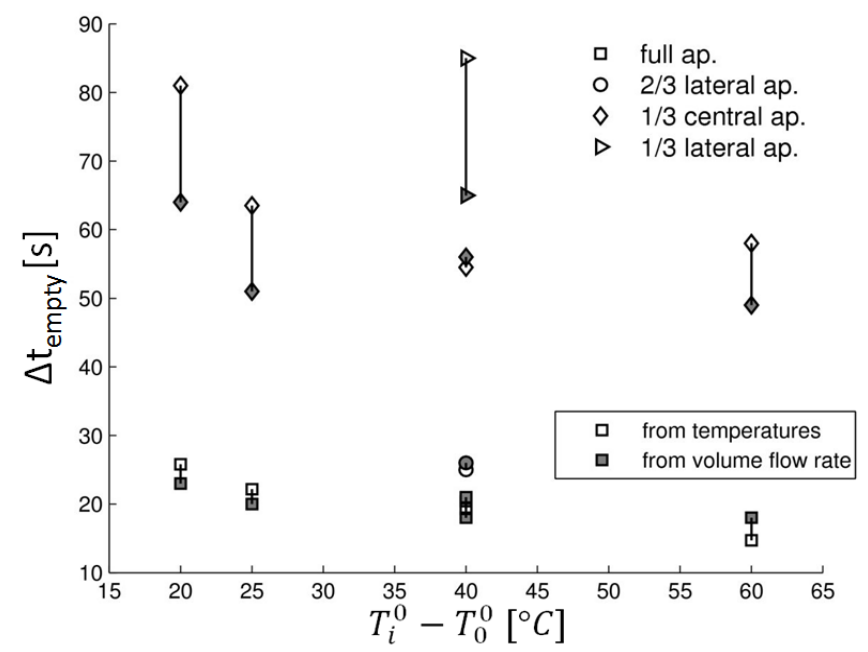

Figure 17: Approximate time period requested to replace the initial air volume inside the truck body. 
Hence, the difference of total pressure across the doorway $\left(\Delta P_{t o t}\right)$, i.e. the driving pressure, is:

$\Delta P_{\text {tot }}=\left(\rho_{i}-\rho_{o}\right) g|z|$,

and the corresponding mean value over the height yields:

$\overline{\Delta P_{t o t}}=\left(\rho_{i}-\rho_{o}\right) g H / 4$.

As the air velocity increases, part of the total pressure is converted to dynamic pressure $\left(\Delta P_{d y n}\right)$. According to Bernoulli, along a stream line we have:

$\Delta P_{d y n}=\frac{1}{2} \rho u^{2}$.

Here, it is assumed that the velocity $(u)$ is roughly equal to the normal component relative to the doorway plane. Moreover, it is supposed that the dynamic pressure always evolves linearly with the height when moving from zero to $\Delta P_{\text {total }}$, which gives:

$\overline{4 P_{d y n}} \frac{z}{H}=\frac{1}{2} \rho u^{2}$,

from which the velocity is deduced

$u=\sqrt{\frac{8 \overline{\Delta P_{d y n}} z}{\rho H}}$.

Then, integrating over a half of the height, and introducing a discharge coefficient $\left(C_{D}\right)$, the volume flow rate can be expressed as:

$\dot{V}=C_{D} \frac{A_{a p}}{3} \sqrt{\frac{4 \overline{\Delta P_{d y n}}}{\bar{\rho}}}$,

where $\bar{\rho}$ is the mean density defined as:

$\bar{\rho}=0,5\left(\rho_{i}+\rho_{o}\right)$.

Finally the mean dynamic pressure is re-written as a function of the volume flow rate as follows:

$\overline{\Delta P_{d y n}}=\left(\frac{\dot{V}}{A_{a p}}\right)^{2}\left(\frac{3}{2} \frac{1}{C_{D}}\right)^{2} \bar{\rho}$.

Force balance

For the sake of simplicity, a mass inertia is attributed to the inside air volume located throughout the opening $\left(A_{a p} L\right)$. This mass is assumed to move with the same superficial velocity as the air flowing through the opening $\left(2 V / A_{a p}\right)$. Then, the acceleration of this mass must be equal to the static pressure difference across the doorway $\left(\Delta P_{\text {static }}\right)$. This gives:

$\overline{\Delta P_{\text {static }}} A_{a p}=\left(A_{a p} L \rho_{i}\right) \frac{d\left(2 \dot{V} / A_{a p}\right)}{d t}$,

with

$\overline{\Delta P_{\text {static }}}=\overline{\Delta P_{\text {tot }}}-\overline{\Delta P_{d y n}}$

Therefore, introducing Eq. (22) and (28) into Eq. (30) yields

$\left\{\left[\frac{\left(\rho_{i}-\rho_{o}\right) g H}{4}\right]-\left[\left(\frac{\dot{V}}{A_{a p}}\right)^{2}\left(\frac{3}{2} \frac{1}{C_{D}}\right)^{2} \bar{\rho}\right]\right\} A_{a p}=\left(A_{a p} L \rho_{i}\right) \frac{d\left(2 \dot{V} / A_{a p}\right)}{d t}$.

In addition, applying the Boussinesq approximation along with the perfect gas expression, and further assuming for this part of the model that:

$\frac{\rho_{i}}{\bar{\rho}} \approx 1$,

yields to the following expression, where $\overline{\mathrm{T}}$ is approximated by $\mathrm{T}_{\mathrm{o}}$ :

$\left(T_{o}-T_{i}\right)\left(\frac{1}{8} \frac{g}{\bar{T}} \frac{H}{L}\right)-\left(\frac{\dot{V}}{A_{a p}}\right)^{2}\left(\frac{9}{8} \frac{1}{C_{D}^{2}} \frac{1}{L}\right)=\frac{d\left(\dot{V} / A_{a p}\right)}{d t}$. 


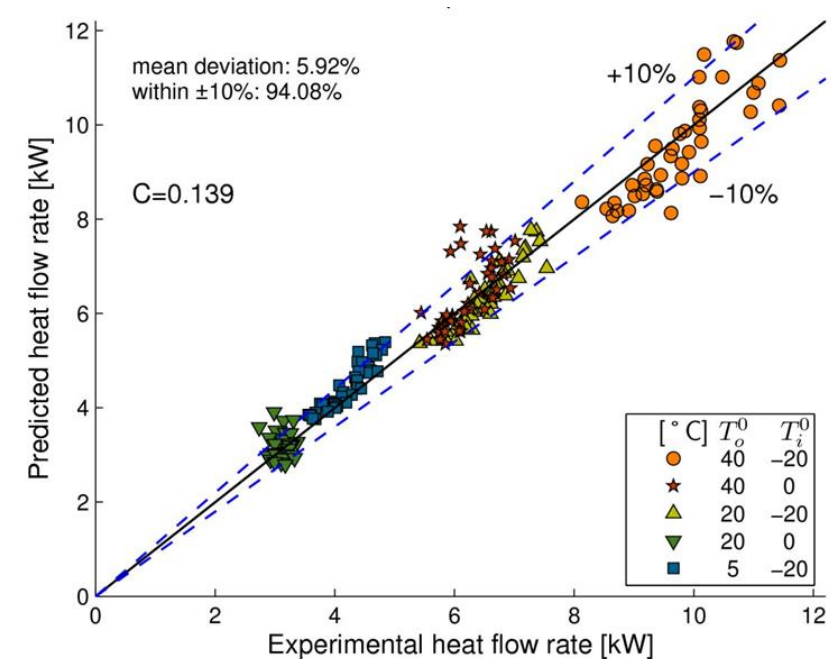

(a)

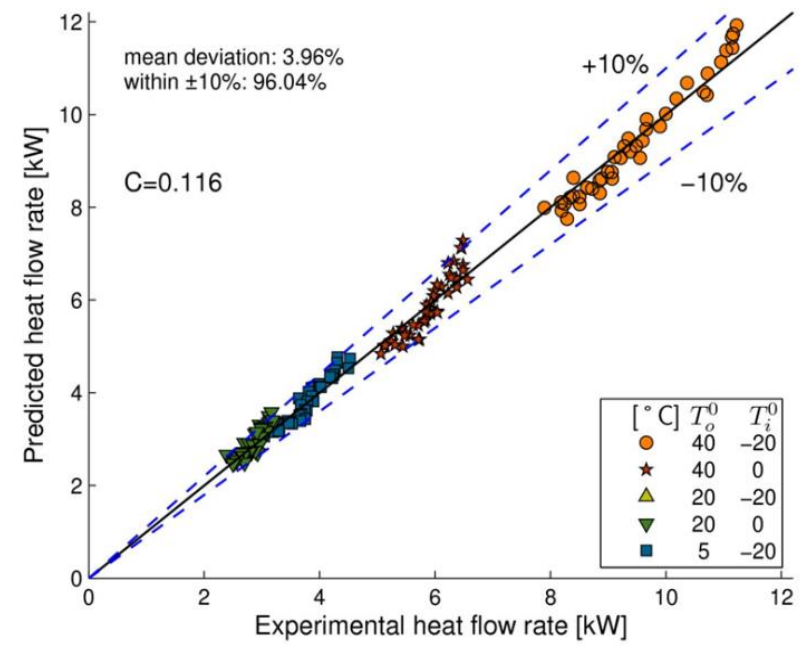

(c)

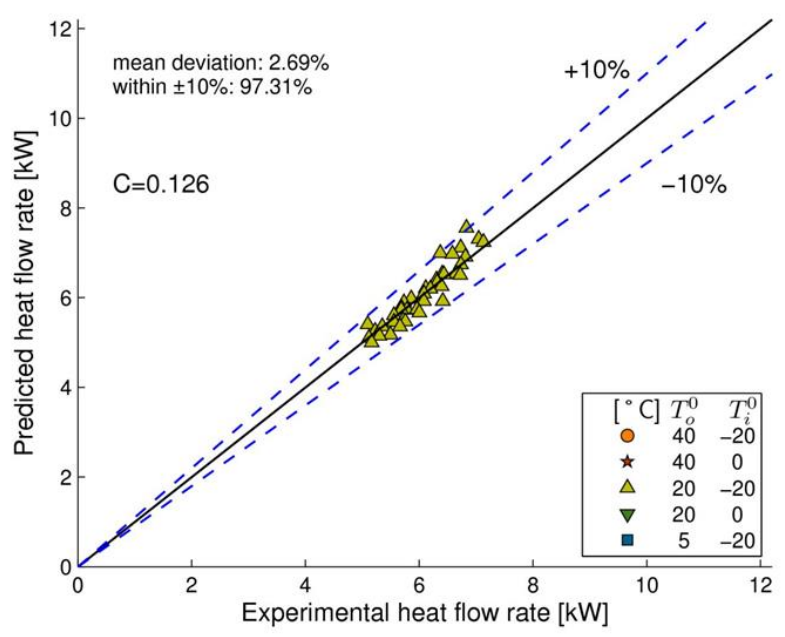

(b)

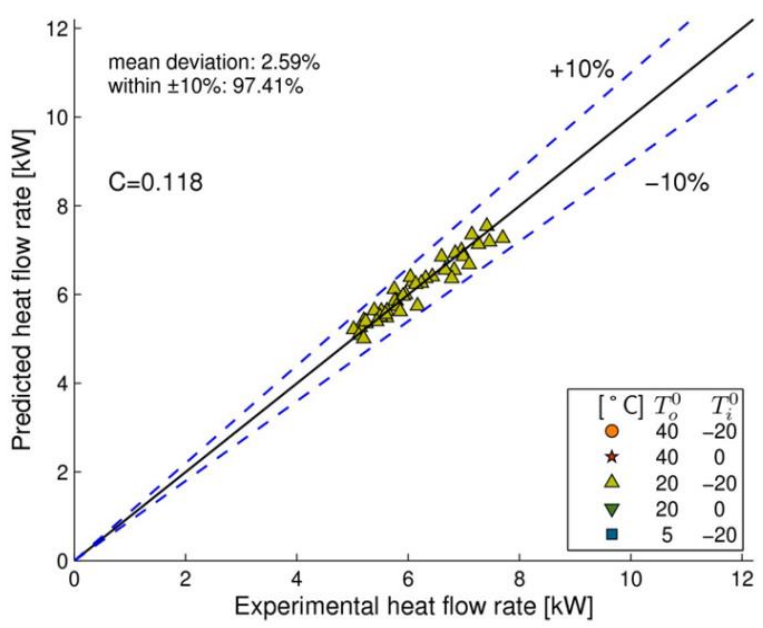

(d)

Figure 18: Comparison between the experimental heat flow rates and the corresponding predictions for the boundary layer flow: (a) full aperture; (b) 2/3 lateral aperture; (c) 1/3 central aperture; (d) 1/3 lateral aperture

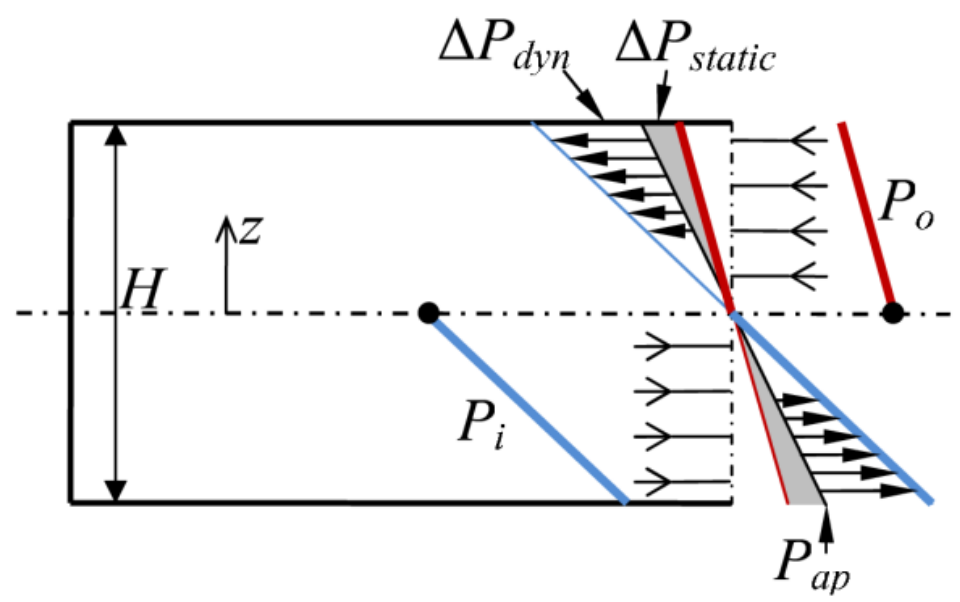

Figure 19: Simplified representation of the buoyancy driven flow. 


\section{Energy conservation}

Assuming that the whole infiltration heat load is applied to the air volume, we obtain:

$$
\dot{V} C p\left(\rho_{o} T_{o}-\rho_{i} T_{i}\right)=V C p \frac{\partial\left(\rho_{i} T_{i}\right)}{\partial t} .
$$

And then, neglecting the density variations, that is:

$\frac{\partial \rho_{i}}{\partial t}=0$ and $\frac{\rho_{o}}{\rho_{i}} \approx 1$,

leads to:

$\frac{\dot{V}}{V}\left(T_{o}-T_{i}\right)=\frac{\partial T_{i}}{\partial t}$

\section{Final system of equation}

Noting $\Delta T_{i}=\left(T_{o}-T_{i}\right)$ and assuming a constant outside temperature yields the following ordinary differential equations (ODE) system:

$\begin{cases}a: & C_{1} \Delta T_{i}+C_{2}\left(\dot{V} / A_{a p}\right)^{2}=\frac{d\left(\dot{V} / A_{a p}\right)}{d t} \\ b: & D_{1} \Delta T_{i}\left(\dot{V} / A_{a p}\right)=\frac{d\left(\Delta T_{i}\right)}{d t}\end{cases}$

where

$$
\begin{aligned}
& C_{1}=\left(\frac{1}{8} \frac{g}{T_{o}} \frac{H}{L}\right) ; \\
& C_{2}=-\left(\frac{9}{8} \frac{1}{C_{D}^{2}} \frac{1}{L}\right) ; \\
& D_{1}=-\left(\frac{1}{L} \frac{W_{a p}}{W}\right) .
\end{aligned}
$$

This ODE system was numerically solved; and the heat flow rate was deduced from the calculated quantities owing to the following expression:

$\dot{Q}=\dot{V} \rho_{o} C p \Delta T_{i}$.

For a more physical approach, it should be considered that the actual temperature of the air flowing outside of the truck body is not equal to the mean inside temperature. So, in addition to the assumption stated above (hypothesis (i)), two other hypotheses were also tested by replacing $\Delta T_{i}$ by a modified variable $\Delta T_{i-o}$ in both Eq. (35b) and Eq. (39). Hypothesis (ii) assumes a perfect stratification of the inside volume. As a consequence, the outlet temperature is that corresponding to the mixing of two layers (hot and cold) located below the neutral level, as depicted in Figure 20 a. The energy conservation gives:

$$
\Delta T_{i-o}=\min \left(\Delta T_{i}^{0}, 2 \times \Delta T_{i}\right)=\left\{\begin{array}{ll}
2 \Delta T_{i} & \text { if } H_{\text {cold }}<H / 2 \\
\Delta T_{i}^{0} & \text { if } H_{\text {cold }}>H / 2
\end{array}\right. \text {. }
$$

As a third option (iii), one could consider that the initial cold air contained in the volume does not mix with the incoming hot air and that the cold air flows out first (Figure $20 \mathrm{~b}$ ). This assumption is expressed as:

$$
\begin{cases}\Delta T_{i-o}=\Delta T_{i}^{0} & \text { if } \int \dot{V} d t<V \\ \Delta T_{i-o}=0 & \text { if } \int \dot{V} d t>V\end{cases}
$$




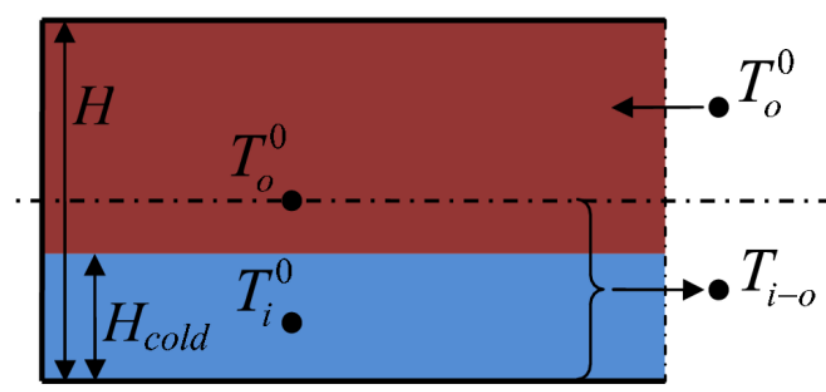

(ii)

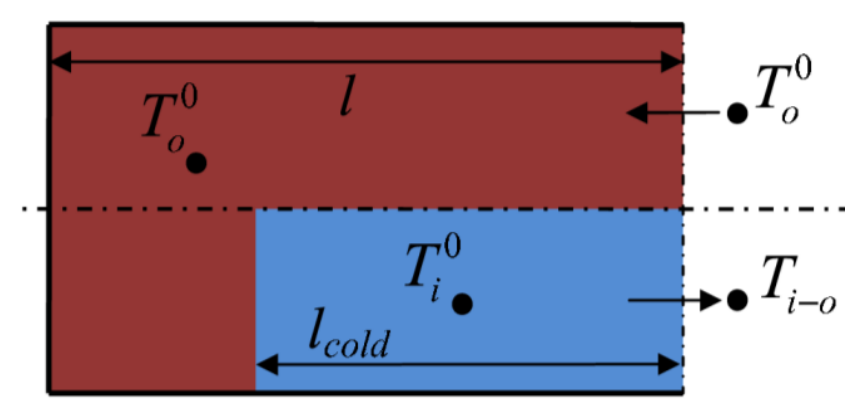

(iii)

Figure 20: Hypotheses regarding the mean temperature of the outlet flow:

(ii) stratification; (iii) cold volume first.

A comparison of the experimental data with the predictions of the model according to the aforementioned hypotheses is displayed in Figure 21 for the baseline case where $C_{D}$ was set to unity. The best compromise was found with hypothesis (ii) to simultaneously fit the time evolution of the volume flow rate (Figure 21 a) and the heat flow rate (Figure $21 \mathrm{~b}$ ). It can be noticed that results given by the CFD model (Figure 7) confirm the hypothesis (i) for short times, while the second hypothesis (ii) is valid later on: the outflow is composed of a mixture of ambient and initial air. Some limits of this simplified approach should be underlined. First, the predicted decay of the volume flow rate is slower than in the experiment. Secondly, the peak of heat flow rate is shifted backward by a few seconds. This is probably due to the fact that, in real conditions, the door opening creates a turbulent mixing between the inlet and outlet flows which reduces the heat infiltration. Obviously, the transient model only represents the buoyancy driven flow and its validity range does not exceed the duration of the unsteady phenomenon. After this period, the inside temperature equalises with the outside temperature, which means that both volume and heat flow rates fall to zero. For the sake of completeness, the data have also been compared with the correlation of Gosney and Olama (1975) for the prediction of the infiltration volume flow rate, as recommended by Hendrix et al. (1989) and Foster et al. (2003):

$\dot{V}=0.221 A_{a p}(g H)^{1 / 2}\left(\frac{\rho_{i}^{0}-\rho_{o}^{0}}{\rho_{i}^{0}}\right)^{1 / 2}\left(\frac{2}{1+\left(\rho_{i}^{0} / \rho_{o}^{0}\right)^{1 / 3}}\right)^{2 / 3}$.

It is worth noting that this equation was initially dedicated to large cold storages and is only valid for a short period of time in the present case (for a small insulated container). As shown in Figure 21, only the peak value is well predicted.

\subsection{Global model}

An attempt was made to combine the two suggested prediction methods for the boundary layer flow and for the buoyancy driven flow. For this purpose, an additional heat source term was introduced in Eq. (35b) standing for natural convection $\left(\dot{Q}_{n c}\right)$ as:

$$
D_{1} \Delta T_{i}\left(\dot{V} / A_{a p}\right)+\frac{\dot{Q}_{n c}}{m C p}=\frac{d\left(\Delta T_{i}\right)}{d t},
$$

where $Q_{n c}^{\cdot}$ was calculated using Eq. (16) with $T_{i}$ as the hot temperature instead of $T_{o}$ in order to represent a heat exchange between the air inside the body volume and the inner wall surface. Then, the discharge coefficient $C_{D}$ was adjusted for each aperture ratio. To better represent the experimental results, the value of $C_{D}=1$ and $C_{D}=0.85$ were respectively chosen for large openings (full and $2 / 3$ lateral apertures) and small openings ( $1 / 3$ central and lateral apertures).

As can be seen in Figure $21 \mathrm{~b}$, the term of natural convection improves the prediction of the heat flow rate with hypothesis (ii) and gives an acceptable fit to the measurements for the whole time span comprising long opening times. However, the volume flow rate is overestimated during the steady-state regime (Figure 21 a). This is due to the fact that the model cannot predict well the volume flow rate if a direct heat exchange exists between the outside air and the body inner wall. Nevertheless, as depicted in

Figure 22, for a small aperture ratio the predicted volume flow rate is closer to the experimental data. In fact, in this case, the direct heat exchange between the outside air and the body walls is restricted. Natural 
convection between the inside volume and the inner wall is more likely which makes the model more suitable.

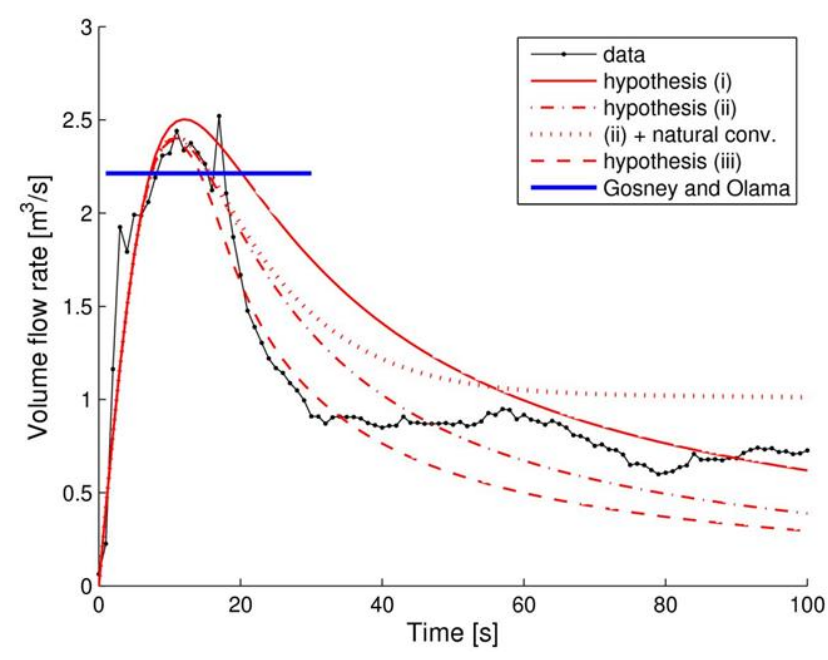

(a)

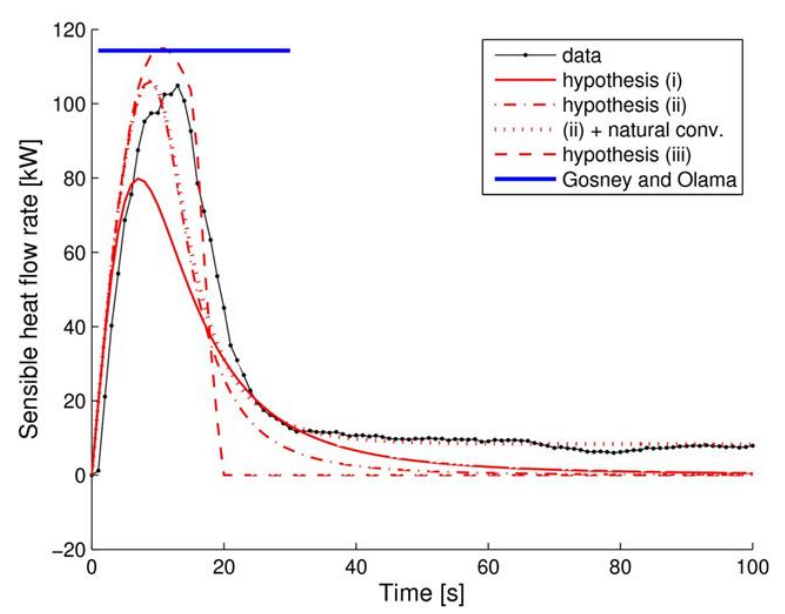

(b)

Figure 21: Comparison between the experimental data and the predictions, for the baseline case: (a) volume flow rate; (b) heat flow rate.

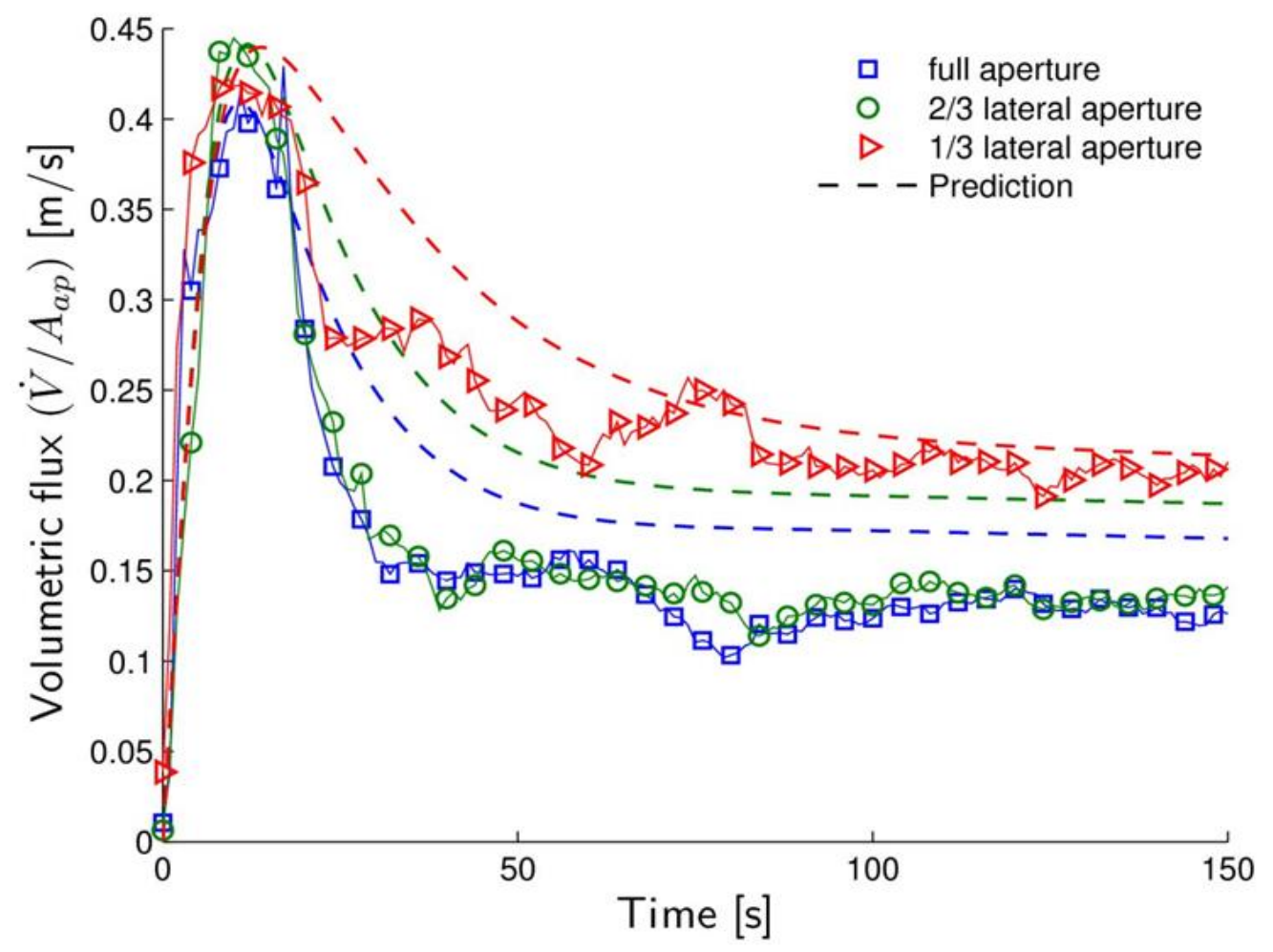

Figure 22: Effect of the aperture ratio on the prediction capability of the model for the base line case.

Regarding the prediction of the heat flow rate, a good agreement with the data is still obtained in a large range of conditions. A qualitative comparison is shown in Figure 23 and Figure 24 respectively for heat flow rates and total infiltration heat loads. Moreover, the deviations between the experimental and the predicted total heat loads over the buoyancy driven flow period are reported in Figure 25 showing a $4 \%$ mean deviation. 


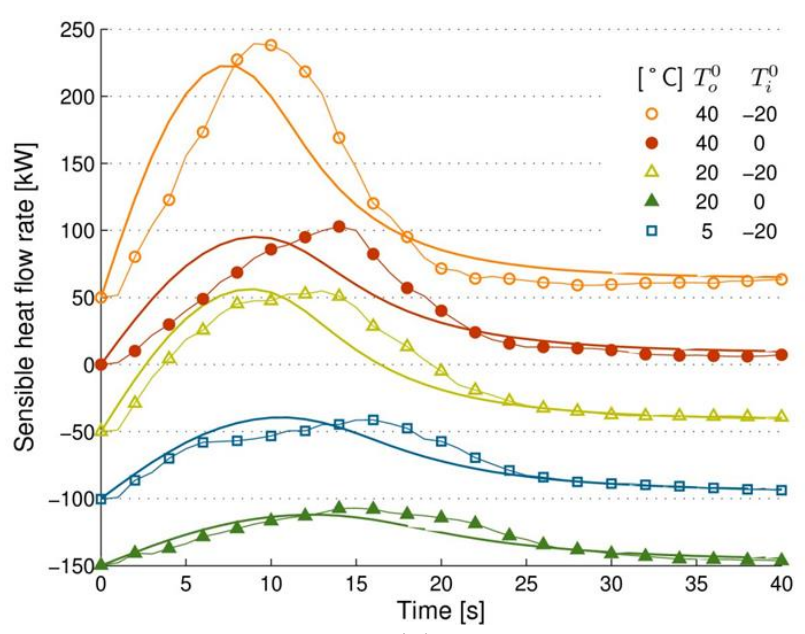

(a)

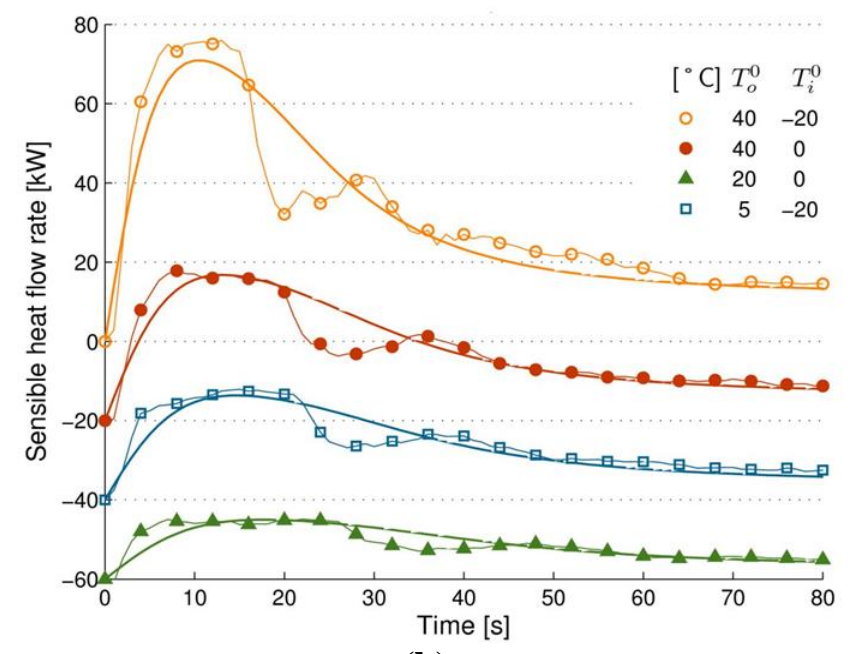

(b)

Figure 23: Heat flow rate predictions as a function of time and comparison with experimental data: (a) full aperture; (b) $1 / 3$ central aperture.

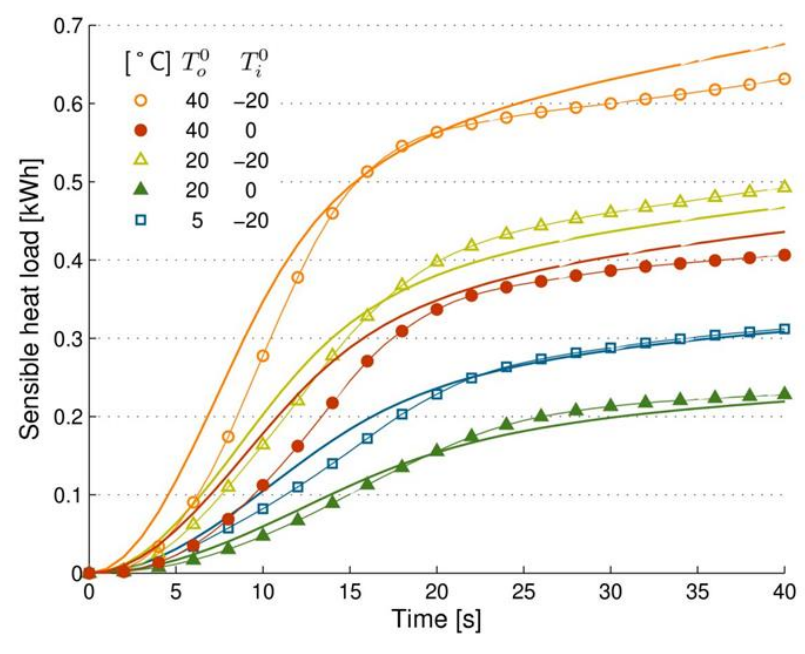

(a)

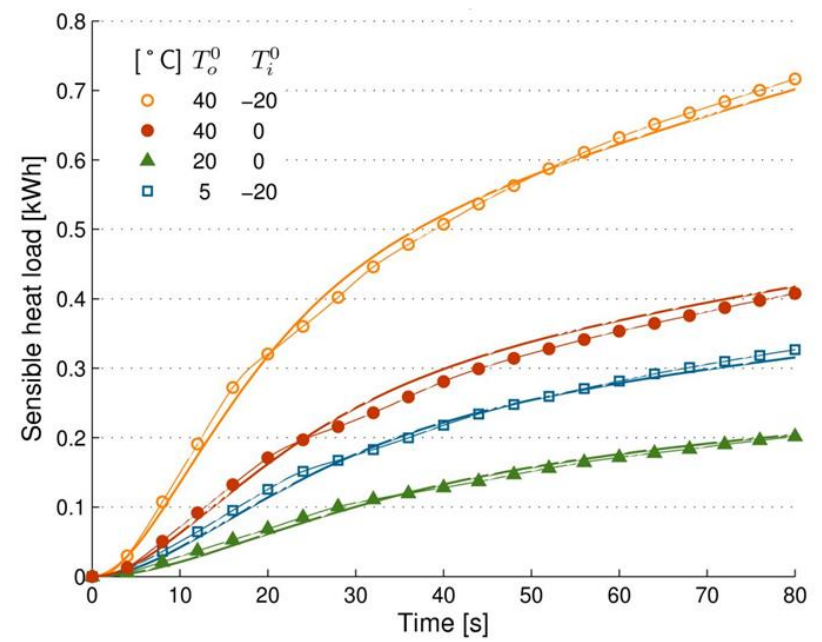

(b)

Figure 24: Total infiltration heat load predictions as a function of the opening time and comparison with experimental data: (a) full aperture; (b) 1/3 central aperture.

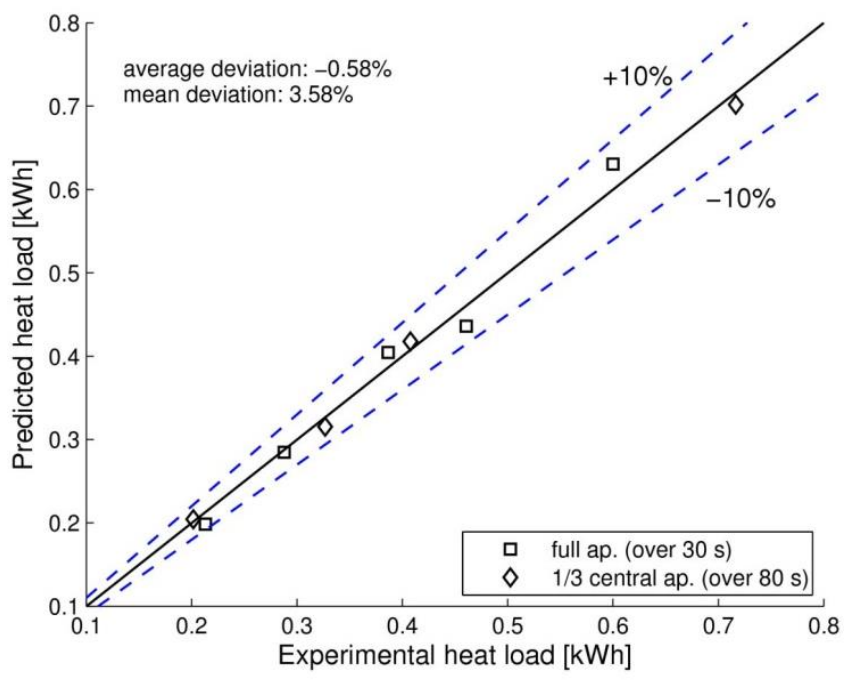

Figure 25: Deviations between the predicted and the experimental infiltration heat loads over the buoyancy driven flow period. 


\section{CONCLUSION}

This work was carried out to study the infiltration heat load during the opening of a refrigerated truck. Experiments and CFD-based simulations were performed for different aperture ratios and different temperature gradients. Regarding the infiltration heat load, the case of small insulated containers like the body of a refrigerated truck should be distinguished from the case of large cold storages. Indeed, in large cold rooms, the infiltration load (or the aperture area) is small compared to the thermal inertia of the inside air (or the inner volume). Moreover, the refrigeration units are operating permanently. Thus, the hypothesis of a fully established flow with no decay is probably a correct assumption. Based on the ideal flow theory, steady-state expressions for density-driven heat infiltrations may be used successfully. The present results show that this assumption is no more valid for truck bodies having small inner volumes compared to the doorway surface area, and having long opening times. In the present case, two different mechanisms were observed regarding heat and mass exchanges:

(i) An unsteady mass exchange between the inside and the outside air volumes appears first, called buoyancy driven flow. During this period, the density difference between the two volumes is the driving force. The volume flow rate reaches a peak value but quickly decays due to the temperature increase inside the truck body. For the tested body, this first stage extends to about $20 \mathrm{~s}$ for the total door opening (aperture width is equal to the body width), and up to about $50 \mathrm{~s}$ for a $1 / 3$ aperture ratio. The CFD model assuming an instantaneous door opening of the door is in good accuracy with the experimental temperature and velocity profiles at the doorway. A very simple ODE model taking into account both mass and thermal inertia was shown to correctly reproduce the experimental infiltration dynamics, provided that the thermal stratification inside the truck body is taken into account;

(ii) A second kind of heat exchange between the outside air volume and the inner wall of the body occurs after, called boundary layer flow. This is basically natural convection over the cold walls of the container. This phenomena appears once the inside air has roughly reached a ceiling temperature of a few Kelvin below the outside temperature. Then, a quasi-steady-state heat transfer is observed until doors are closed, at a time that can reach $10 \mathrm{~min}$ in actual food deliveries. During this period, the heat infiltration is well predicted with a classical expression standing for natural convection over a vertical wall. The CFD model is also in good agreement with the experimental results even if the velocity in the lower part of the opening is underpredicted.

The present study suggests a first theoretical step toward a better understanding and prediction of infiltration heat loads during the opening of truck bodies. It should be pointed out that all the regression coefficients included in the proposed prediction methods are only valid for the specific geometry of the tested body. More work is needed with containers having different aspect ratios to obtain some more general expressions. Additional experiments should be carried out in more complex conditions, for example with a loaded body to better stick to reality. Furthermore, the validation of the CFD model is one-step towards the extension to containers having different aspect ratio and to study the influence of protective devices like plastic strip or air curtains.

\section{ACKNOWLEDGEMENTS}

This research was carried out with financial support from Agence de l'Environnement et de la Maîtrise de l'Energie (ADEME) as part of the programme of research, experimentation and innovation in land transport (PREDIT) initiated by Agence Nationale de la Recherche (ANR). This study was partially led in a project on Truck Refrigeration for Urban Environment (TRUE). Appreciation is due to the partners of the project, Carrier Transicold and Lamberet for providing the truck body and the refrigeration unit, as well as Renault Trucks, François Clavier Conseil, and Marmonier. A special thanks is extended to Nicolas Boudet, head of CEMAFROID Bordeaux, France, for bringing their expertise during the experiments in their ATP facility. The operating staffs are to be commended for their cooperation and interest, always making sure testing could be performed and would be relevant.

\section{REFERENCES}

Azzouz A, Gossé J, Duminil M. 1993, Experimental determination of cold loss caused by opening industrial cold-room doors, Int. J. Refrig. 16: 57-66.

Brown WG, Solvason KR. 1963, Natural convection in openings through partitions - 1 vertical partitions, Int. J. Heat Mass Transf. 5: 859-868. 
Clavier F, Sartre V, Bonjour J. 2011, Infiltration heat load through the doorway of a refrigerated truck protected with an air curtain, Proc. $23^{\text {th }}$ Int. Congr. Refrig,. August 21-26, Prague, ${ }^{\circ} 783,8$ p.

DIN Deutsches Institut für Normung. 2000, Insulated food carriers - Requirements and testing, DIN 8959 Standard.

Ducoulombier M, Sartre V, Bonjour J. 2011, Experimental investigation of the infiltration heat load during the oppenig of a refrigerated truck body, Proc. $23^{\text {th }}$ Int. Congr. Refrig,. August 21-26, Prague, $n^{\circ} 392,8 \mathrm{p}$.

Foster, AM, Barrett R, James SJ, Swain MJ. 2002, Measurement and prediction of air movement through doorways in refrigerated rooms, Int. J. Refrig. 25: 1102-1109.

Foster AM, Swain MJ, Barrett R, James SJ. 2003, Experimental verification of analytical and CFD predictions of infiltration through cold store entrances, Int. J. Refrig. 26: 918-925.

Fritzsche C, Lilienblum W. 1968, Neun Messungen zur Bestimmung der Kalterluste and Kühlraumtüren, Kältetechnik-Klimatiserung. 20: 279-286.

Gosney WB, Olama HAL. 1975, Heat and enthalpy gains through cold room doorway, Proc. Inst. Refrig. 72: $31-41$.

Hendrix WA, Henderson DR, Jackson HZ. 1989, Infiltration heat gains through cold storage room doorways, ASHRAE Trans. 95: 1155-1168.

Incropera FP, DeWitt DP. Fundamentals of Heat and Mass Transfer, $5^{\text {th }}$ Edition. 2001, John Wiley \& Sons, 944p, ISBN 978-0471386506

Knoche K F. Renz U, Schneider, F. Properties of Mass. In: Engineering Reference Book on Energy and

Heat. Association of German Engineers, Society for Energy and Technologies, Düsseldorf, 1992, 273 p.

ISBN 3-18-400948-3.

Lafaye de Micheaux, T, Sartre, V, Stumpf, A, Bonjour, J. 2013. Numerical investigation of heat and mass transfer in a refrigerated truck compartment, Proc. $2^{\text {nd }}$ Int. Congr. Cold Chain, 8p.

Lafaye de Micheaux, T, Sartre, V, Stumpf, A, Bonjour, J, Haberschill, Ph. 2013, Modélisation des transferts de masse et de chaleur dans une semi-remorque frigorifique. Revue générale du froid, 1139: 24-31.

Launder, B E, Spalding, D B. 1974, The numerical computation of turbulent flows. Comput. Methods Appl. Mech. Eng., 3(2), 269-289. doi:10.1016/0045-7825(74)90029-2

Mc Adams WH. 1961, Transmission de la chaleur, Dunod.

Pham QT, Oliver DW. 1983, Infiltration of air into cold stores, Proc. 16th Int. Congr. Refrig. 4: 97-72.

Roy Munson, B, Huebsch, WW, \& Rothmayer, AP. Fundamentals of Fluid Mechanics, $7^{\text {th }}$ Edition. 2012, John Wiley \& Sons, 792p, ISBN 978-1118399712.

Repice C, Stumpf A. 2007, Energy efficiency in transport refrigeration, Proc. Int. Congr. Refrig. (Paper No. ICR07-D2-362).

Shih, T-H., Liou, W. W., Shabbir, A., Yang, Z., \& Zhu, J. 1995, A new k- $\epsilon$ eddy viscosity model for high reynolds number turbulent flows. Comput Fluids, 24(3), 227-238. doi:10.1016/0045-7930(94)00032-T

Tamm W. 1965, Air flow with air curtains to protect cold rooms, Proc. 11th Int. Congr. Refrig. 2: 10251038.

Tassou SA, De-Lille G, Ge YT. 2009, Food transport refrigeration - Approaches to reduce energy consumption and environment impacts of road transport, Appl. Therm. Eng. 29: 1467-1477.

Tso CP, Yu SCM, Poh HJ, Jolly PG. 2002, Experimental study on the heat and mass transfer characteristics in a refrigerated truck, Int. J. Refrig. 25: 340-350.

United nations. Agreement on the International Carriage of Perishable Foodstuffs and on the Special Equipment to be used for such Carriage. United Nation Publication. 2013, 91 p, http://www.unece.org/trans/main/wp11/atp.html (10/01/14), ISBN 978-92-1-139147-3. 